\title{
Developing predictive insight into changing water systems: use-inspired hydrologic science for the Anthropocene
}

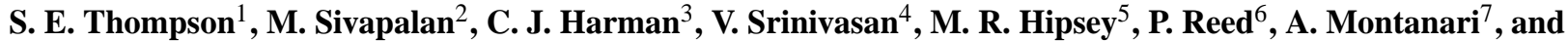 \\ G. Blöschl ${ }^{8}$ \\ ${ }^{1}$ Department of Civil and Environmental Engineering, 661 Davis Hall, University of California, \\ Berkeley, California, 94720, USA \\ ${ }^{2}$ Department of Geography and Geographic Information Science and Department of Civil and Environmental Engineering, \\ University of Illinois at Urbana-Champaign, Hydrosystems Laboratory, N. Matthews Avenue, Urbana, Illinois, 61801, USA \\ ${ }^{3}$ Department of Geography and Environmental Engineering, Johns Hopkins University, Baltimore, Maryland, USA \\ ${ }^{4}$ Ashoka Trust for Research in Ecology and the Environment, Bangalore, India \\ ${ }^{5}$ School of Earth and Environment, The University of Western Australia, 6009 Crawley, Australia \\ ${ }^{6}$ School of Civil and Environmental Engineering, Cornell University, Ithaca, New York, USA \\ ${ }^{7}$ Department DICAM, University of Bologna, Bologna, Italy \\ ${ }^{8}$ Institute of Hydraulic Engineering and Water Resources Management, Vienna University of Technology, Vienna, Austria
}

Correspondence to: S. E. Thompson (sally.thompson@berkeley.edu)

Received: 28 May 2013 - Published in Hydrol. Earth Syst. Sci. Discuss.: 20 June 2013

Revised: 4 November 2013 - Accepted: - Published: 12 December 2013

\begin{abstract}
Globally, many different kinds of water resources management issues call for policy- and infrastructure-based responses. Yet responsible decision-making about water resources management raises a fundamental challenge for hydrologists: making predictions about water resources on decadal- to century-long timescales. Obtaining insight into hydrologic futures over $100 \mathrm{yr}$ timescales forces researchers to address internal and exogenous changes in the properties of hydrologic systems. To do this, new hydrologic research must identify, describe and model feedbacks between water and other changing, coupled environmental subsystems. These models must be constrained to yield useful insights, despite the many likely sources of uncertainty in their predictions. Chief among these uncertainties are the impacts of the increasing role of human intervention in the global water cycle - a defining challenge for hydrology in the Anthropocene. Here we present a research agenda that proposes a suite of strategies to address these challenges from the perspectives of hydrologic science research. The research agenda focuses on the development of co-evolutionary hydrologic modeling to explore coupling across systems, and to address the implications of this coupling on the long-time behavior of the coupled systems. Three research directions support
\end{abstract}

the development of these models: hydrologic reconstruction, comparative hydrology and model-data learning. These strategies focus on understanding hydrologic processes and feedbacks over long timescales, across many locations, and through strategic coupling of observational and model data in specific systems. We highlight the value of use-inspired and team-based science that is motivated by real-world hydrologic problems but targets improvements in fundamental understanding to support decision-making and management. Fully realizing the potential of this approach will ultimately require detailed integration of social science and physical science understanding of water systems, and is a priority for the developing field of sociohydrology.

\section{Predictions under change}

The effect of human activities on the water cycle is deepening and widening rapidly across the planet, driven by increased demands for energy (King and Webber, 2008; Koutsoyiannis et al., 2009), water (Jackson et al., 2001), food (Vörösmarty et al., 2001) and living space (Zhao et al., 2001), and the unintended consequences and secondary effects of land use and 
climate change. Cumulatively, these demands result in increased human appropriation of water resources, significant modification of landscapes, and a strong human imprint on water cycle dynamics from local to global scales (Carpenter et al., 2011; Falkenmark and Lannerstad, 2005; Röckstrom et al., 2009; Vörösmarty et al., 2010). The combination of these effects mean that the world faces a sharp decline in water security (Gleick and Palaniappan, 2010; Postel and Wolf, 2001), which is likely to be most severe in the least resilient of nations (Milly et al., 2002, 2008; Sheffield and Wood, 2008).

The increasing human impacts on the water cycle demand effective management, such as the development of infrastructure, policy and law to respond to contemporary problems and create frameworks for future management. Management actions taken today - whether infrastructure- or policyrelated - will have long legacies (Swyngedouw, 2009). The lifetimes of artificial reservoirs, for instance, are on the order of 10 s to 100s of years (Einsele and Hinderer, 1997). Similarly, the laws governing water rights in the western United States have had decadal- to century-scale effects $(\sim 200 \mathrm{yr}$ for the Prior Appropriation Act, $\sim 90 \mathrm{yr}$ for the Law of the River), where incorrect assumptions about flow continue to constrain water management (Garner and Ouellette, 1995; Hundley, 2009; Tarlock, 2002). Thus, the legacies of historical water resource management decisions contribute to contemporary water management problems (Srinivasan et al., 2012). It is likely that humankind will be constrained by water resource availability for the foreseeable future. Contemporary water resources management decisions should therefore attempt to account for their impacts on time horizons commensurate with those of their legacies. These time horizons encompass a period in which we anticipate dramatic changes in climate, population, land uses, and energy and food demand (Huang et al., 2011). Indeed, the human-driven changes in water, nutrient, energy cycles, and landscape evolution may now overwhelm natural variability, leading to the contemporary geologic era being labeled the Anthropocene the human era (Crutzen and Stoemer, 2000; Poff et al., 2013; Röckstrom et al., 2009; Vitousek et al., 1997; Vörösmarty et al., 2010; Zalasiewicz et al., 2010). To make good decisions about water management today requires a drastic improvement in our ability to predict the dynamics of water resources on long timescales, in the presence of rapid change in multiple elements of the water system, and subject to the direct and indirect influence of human activity (Milly et al., 2008; Wagener et al., 2010). To continue to make good water management decisions as projected changes impact water systems behavior also requires detecting and attributing emergent changes (Maurer et al., 2007), making predictions about their effects on hydrology, and altering management decisions accordingly. The complexity of these issues means that we have taken a broad view of the term "prediction". At one extreme, we recognize that traditional, deterministic forecasts are likely to be impossible for complex systems containing human agents, particularly on long timescales. At the other extreme, we disagree with the assertion that deep uncertainty would render improved understanding, modeling and predictive assessments meaningless. Instead, we suggest a middle path that asserts that the combination of specific initial and boundary conditions and process interactions among physical, socio-cultural and ecological domains, will constrain the possible future trajectories of water systems, rendering some outcomes more (or less) likely. Identification of the critical initial and boundary conditions and interacting processes is a non-trivial task that itself requires a significant research focus (see Sect. 3). Assuming the problem can be suitably defined, and depending on the timescale of the prediction, which affects the development of uncertainty, such constraints may provide a basis for visualization, understanding and intervention, and for the formulation of a constrained range of potential future scenarios for analysis. Indeed, the lead-time of the prediction is the fundamental driver of the interactions between model structure, prediction goals and increase of uncertainty. We refer to these modest goals as the development of predictive insights, which include predictions of a phenomenological or qualitative nature (Kumar, 2011).

The hydrological prediction frameworks that are widely applied for managing water resources today derive from a reductionist paradigm that attempts to upscale microscopic process knowledge to large spatial and temporal scales (Wagener et al., 2010), and may not be well aligned towards developing predictive insight into complex systems. Several commentators have already called for new ways to do water science that are based on exploration of patterns, macroscopic or "top-down" hydrologic prediction and comparative approaches (Blöschl, 2006; McDonnell et al., 2007; Sivapalan et al., 2003), with the intention that such techniques could support hydrologic predictions in the Anthropocene (Killeen and Abrajano, 2008; Wagener et al., 2010; Reed and Kasprzyk, 2009). Such a research approach, however, raises pragmatic questions. For instance, the respective roles of single-investigator research approaches versus community-wide "big science" endeavors in this arena must be better defined, since team science approaches may be better suited to synthesis research (Blöschl, 2006; Torgersen, 2006). Use-inspired hydrologic science must also be careful to avoid devaluing "pure science" approaches to hydrology (Dunne et al., 1998). Thus, developing predictive insight to support water management in the Anthropocene not only poses fundamental scientific challenges, but also non-trivial practical challenges for the water science community.

As a response to these issues, we convened a series of workshops for the hydrologic community in 2009-2010 to discuss the grand challenge of making hydrological predictions in the Anthropocene (Sivapalan, 2011). This article represents a distillation of the ideas generated from this large, grassroots effort. Here we firstly identify core impediments to hydrologic prediction in the Anthropocene and argue that 
there are tangible research methods available to the hydrologic research community that can begin to address these problems. Secondly, we propose that a "use-inspired" approach towards the planning and execution of this research (Stokes, 1997) provides a way to simultaneously advance fundamental knowledge and its applicability to water resources management, and thus navigating some of the tensions that arise between doing science to expand fundamental knowledge, and doing science to improve human and environmental well-being. The agenda outlined here aspires to improve the capacity of hydrologic researchers to meet the prediction needs posed by water resources management challenges. It is focused, however, on addressing gaps that can be identified within the current portfolio of physical hydrologic science, its theory, tools, methods and capabilities. It does not attempt to address improved and integrated approaches for water resources management or the science-policy interface. Numerous authors have highlighted the importance of water resources management that accounts for socio-cultural contexts, needs and equity (Gual and Norgaard, 2010; Lane, 2013; O'Brien, 2013; Pahl-Wostl et al., 2007; Pahl-Wostl and Hare, 2004; Tippett et al., 2005) by recognizing that social and hydrologic systems are in many cases inseparable. How to most effectively communicate and collaborate across science, policy and stakeholder communities to achieve beneficial water resource management outcomes is a critically important question, but one that lies beyond the scope of this scientifically oriented paper.

\section{Scientific needs and challenges}

Several scientific challenges derive directly from the need to develop predictive insight on the decadal- to century-scale time frames commensurate with the lifetimes of our water management decisions. As argued above, century-long timescales encompass periods of time over which multiple environmental subsystems are anticipated to change as a direct or indirect result of human activity. These changes mean that the hydrologic system, taken as a whole, is characterized by time-dependent properties that may change rapidly relative to the timescales on which prediction is desired. Following Milly et al. (2008), we will refer to this time-dependence of system properties as "non-stationarity". Although there is a long literature dealing with non-stationary modeling in hydrology (Clarke, 2007; Cohn and Lins, 2005; Klemes, 1974; Koutsoyiannis, 2006), coping with non-stationarity still generates several specific challenges related to its interpretation and description: (i) firstly, predicting the effects of change in interconnected environmental subsystems on hydrologic behavior. To do this, we must (ii) secondly identify and develop functional descriptions for change, which may imply parameterizing the interactions and feedbacks between interconnected subsystems. Thirdly, (iii) the interaction of multiple interconnected subsystems with many degrees of freedom is likely to amplify uncertainty in our predictions, and techniques to constrain this uncertainty must be developed. Finally, (iv) interconnected environmental subsystems include the special case of human-water interactions. Improving our understanding of these interactions is a particularly difficult and important challenge worthy of special consideration (Leung et al., 2013).

\subsection{Challenge 1: non-stationarity}

Over the next $10-100 \mathrm{yr}$, most hydrologic systems will be exposed to continuous (albeit uncertain) changes in climatic forcing. Climate change signals are now detectable in some global and regional hydrologic processes (Maurer et al., 2007; Seneviratne et al., 2010). New patterns of rainfall extremes are predicted in many regions of the world (Dominguez et al., 2012; Huntingford et al., 2006). Although their behaviors do not exhibit a consistent global tendency (Sun et al., 2012), such patterns have a direct impact on rainfall statistics, which will no longer reflect their historical distribution. Making predictions on century-long timescales requires propagating these changes into hydrological predictions, carrying out impact studies which involve significant unknowns and uncertainties (Blöschl and Montanari, 2010). Significantly non-linear responses to these climatic changes alone are anticipated (Fig. 1a), making the extrapolation of historical data to future scenarios challenging. Contemporary approaches that perform this extrapolation directly, e.g., historically based frequency analysis approaches (Milly et al., 2008), or indirectly, through calibrating models to historical data (Wagener, 2007), are thus problematic.

Climate and land use change directly impact hydrology through changing the forcing and response of hydrologic systems. Moreover, they are also likely to induce further changes in a range of physical, ecological and social processes. Making hydrologic predictions on century-long timescales is therefore not only a matter of developing modeling approaches that are robust to non-stationarity in the forcing variables, but also requires addressing how these changes propagate into the structure and properties of catchments (Sivapalan et al., 2003). For example, climate and land use changes are likely to promote changes in vegetation and ecological communities and their properties (Loarie et al., 2009; Donohue et al., 2013). Vegetation composition in a catchment can change over decadal timescales, (Foley et al., 2000; Rose et al., 1995; Thompson and Katul, 2008). Vegetation composition can also have large impacts on water resources - e.g., $30 \%$ decline in annual runoff and $60 \%$ decline in peak flows following pine invasion of grasslands (Fahey and Jackson, 1997). "Second-order" effects of climate change on hydrology - such as a climate-induced change in vegetation community composition that alters land surface water budget partitioning - can thus occur rapidly compared to the $100 \mathrm{yr}$ prediction horizon. Describing second-order effects requires a predictive framework that extends beyond 
A

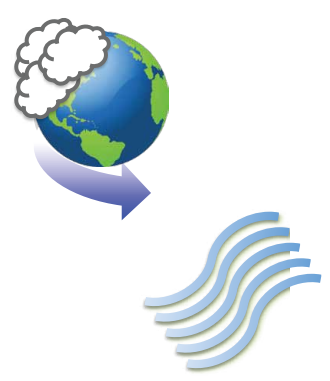

B

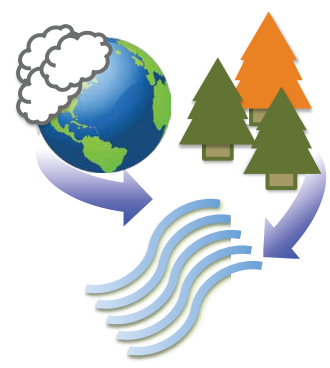

C

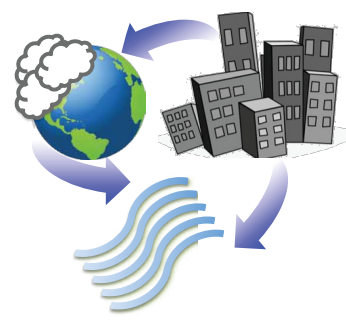

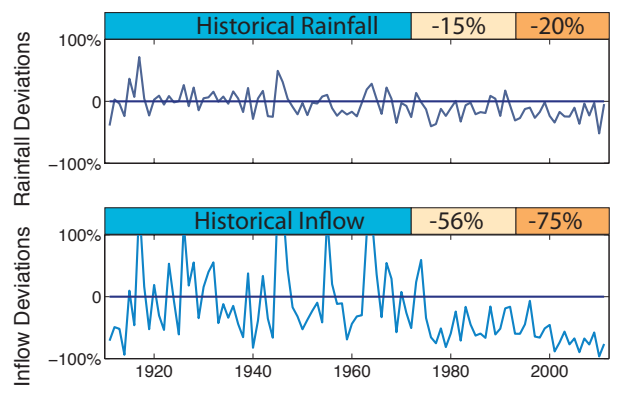
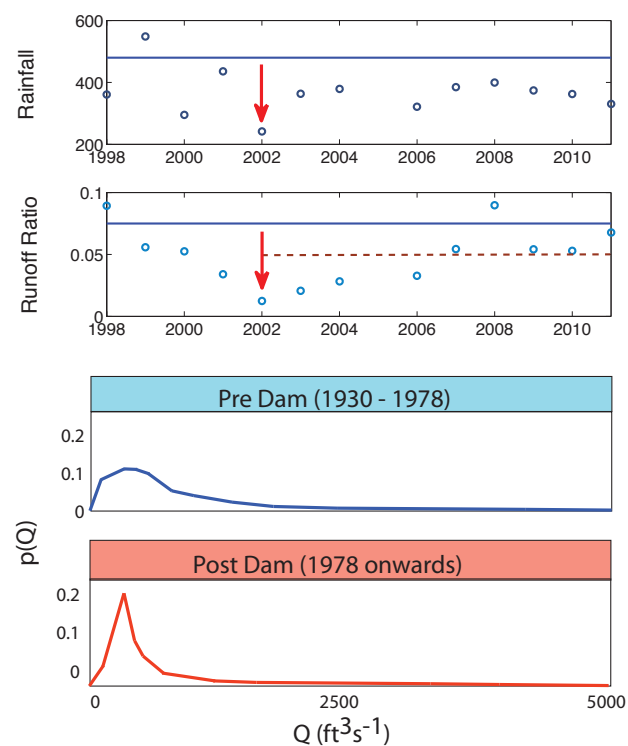
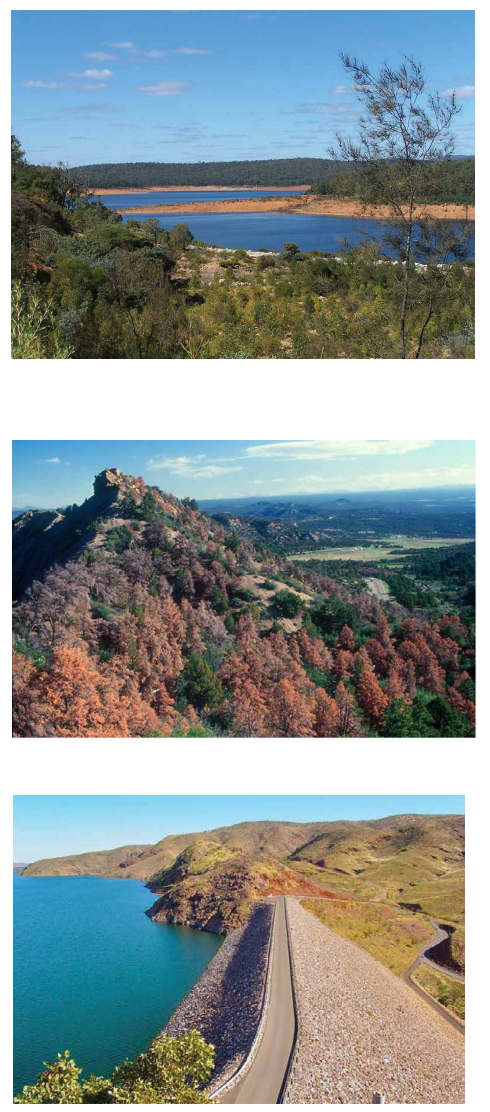

Fig. 1. Three fundamental challenges facing hydrological predictions in the Anthropocene. (A) Changing boundary conditions, illustrated by the $20 \%$ decline in annual rainfall in Western Australia, generate strongly non-linear responses in hydrological systems - in this case, a $75 \%$ decline in reservoir inflows, forcing water supply to transition from surface water resources to desalination and groundwater extraction. (B) Propagation of changing boundary conditions into changes in interacting systems, illustrated here by Piñon pine mortality in the Southwest USA. Despite significant loss of forest cover and transpiring areas, runoff ratios in these regions remain at historically low levels, with 1969 the degree of runoff suppression proportional to forest mortality. (C) The potential for human action to generate large changes in hydrology in ways that hydrologists are not well equipped to predict. For instance, dam construction near the city of Raleigh, North Carolina has transformed the streamflow PDF in ways that could not be predicted from historical observation of the streamflow alone.

purely hydrologic dynamics. The interactions of coupled systems are often complex (Tucker and Slingerland, 1997), and may be counterintuitive. For instance, in direct opposition to the pine invasion example quoted above; drought mortality of Piñon pine in the Southwest USA caused a $50 \%$ decline in runoff ratio (Guardiola-Claramonte et al., 2011) (Fig. 1b). Second-order effects of climate or land use change thus present a major scientific knowledge gap (Foley et al., 2003; Lloyd and Farquhar, 2008; Gupta et al., 2000) which is only exacerbated when considering the potential feedbacks between human and hydrologic systems (Fig. 1c, and Sect. 2.4).

\subsection{Challenge 2: identifying, describing and accounting for feedbacks}

Addressing both first- and second-order effects of nonstationarity greatly expands the domain of hydrologic inquiry, and generates a series of new challenges of its own: (i) identifying whether or not systems are coupled to each other; (ii) describing the mechanisms that mediate this coupling; and (iii) parameterizing these functional relationships. The explosion of research activity in interdisciplinary subfields of hydrology-ecohydrology (Smettem, 2008; Rodriguez-Iturbe, 2000), eco-geomorphology (Wheaton et al., 2011), eco-hydraulics (Nepf, 2012), hydro-climatology (DeAngelis et al., 2010), hydro-pedology (Lin et al., 2005), and socio-hydrology (Sivapalan et al., 2012) etc. - reflects a growing understanding of the mechanisms and importance of coupling between hydrologic and other environmental 
subsystems. However it is unclear whether the processes generally targeted by interdisciplinary hydrology describe all relevant interactions exhaustively. For instance, adopting a data-driven approach, Ruddell and Kumar (2009a, b) identified multiple process couplings on widely varying timescales that described the interaction of agricultural crops with the atmospheric boundary layer. Many of these couplings did not map to known or hypothesized land-atmosphere interaction pathways. We may not, therefore, understand the full range of process coupling, even in relatively well-studied coupled systems.

Process-based investigations will not identify modes of coupling that investigators do not deliberately look for. Databased investigations will not identify the presence of unobserved coupling. Thus, it is likely that some feedbacks will only be identifiable if their effects change. Identifying unanticipated interactions as they emerge can be challenging, since observation systems are often optimized towards the status quo, and treat deviations from the status quo as erroneous or aberrant. For example, a combination of uncertainties about satellite performance, anticipated gradual rather than rapid ozone loss due to CFC chemistry, and erroneous ground-based measurements of ozone concentrations delayed identification of the Antarctic ozone hole via NASA measurements (Moehring, 1990). It is a challenge to find observation and inference techniques that would avoid similar delays in hydrologic systems.

Assuming the presence of coupling can be identified, the relationships that lead to this coupling must be functionalized, and ultimately represented in terms of measurable physical quantities. Functionalization and parameterization are non-trivial challenges that generally require many observations and dedicated sets of experimentation and investigation (Thompson et al., 2010). Due to the large efforts required to generate these functional relationships and parameters, constraining the set of target processes towards those which will significantly change hydrological dynamics over the timescales of interest is another challenge posed by interconnected systems.

\subsection{Challenge 3: uncertainty, predictability and observations of interconnected systems}

The dynamics of hydrological systems arising from a coevolving complex of interconnected processes pose significant challenges in terms of uncertainty and predictability. Predictions made for coupled, high-dimensional systems are likely to exaggerate the already formidable problem of uncertainty in hydrological models (Beven, 1993, 2006b; Montanari, 2011; Montanari et al., 2009). Coupling additional processes into hydrological prediction systems will increase the number of parameters, and multiply the challenges of calibration and validation. It is likely to exacerbate uncertainty purely due to the complex and coupled nature of the modeling systems (Wagener, 2007; Beven, 1993,
2007). In particular, the uncertainty and error arising from predictions made by static models will grow over time as catchments change (due to changing climate, land use or their second-order effects) and the model assumptions diverge from reality.

Despite this uncertainty, water resource management will still require quantitative predictions or assessments of plausible futures to assist in decision-making. While it may never be feasible to make predictive $100 \mathrm{yr}$ time series predictions of hydrologic response under these conditions, improving short timescale predictions will be essential for evaluation, adaptation and ongoing water resources management (Dessai et al., 2009; Lindenmayer and Likens, 2009; Tanaka et al., 2006). Quantifying and constraining the uncertainty in these predictions provides a feasible, yet still challenging goal.

The counterweight to predictive uncertainty is provided by observations of hydrologic systems. To use observations to constrain uncertainty, diagnose model shortcomings and identify change requires overcoming several limitations. Firstly, it is unclear how to prioritize limited resources for observations towards those of the highest value or greatest need in constraining uncertainties or adapting predictive frameworks (Kollat et al., 2011; Mishra and Coulibaly, 2009; Reed et al., 2006; Reed and Kollat, 2012). Secondly, it is unclear which features of model output offer the most diagnostic insight, particularly when attempting to identify the effects of change (Gupta et al., 2008). Most current diagnostic efforts rely on evaluation of flow time series (Maurer et al., 2007; Moss, 1979a, b), which represent only a small component of the information within a model. New metrics are needed that can evaluate the ability of models to represent non-stationary water systems (Laio and Tamea, 2007; Montanari and Koutsoyiannis, 2012; Sikorska et al., 2013). Finally, observations will be essential to identify the presence of events and trends that were not predicted. Observations can also be used to correct the inherent shortcomings of predictive tools, through conventional or next-generation data assimilation approaches and model diagnostics (Kollat and Reed, 2008; Reed and Kasprzyk, 2009). Thus, the challenge of managing uncertainty relates to the challenge of combining all sources of predictive insight - data and model derived - to constrain uncertainty, improve models, identify important and unexpected transitions and to make quantitative predictions over short(er) timescales.

\subsection{Challenge 4: social factors underlying coupled human-water system behavior}

Addressing the interaction between people and water systems is critical due to the overwhelming direct and indirect influence of human activities on the water cycle - as illustrated for the impact of reservoir construction in Fig. 1c (Vörösmarty et al., 2000, 2010). Yet there is at present limited understanding of the major modes of interaction between human and hydrologic systems on long timescales, and 
significant challenges arise when attempting to develop predictions about this interaction. These challenges are (i) pragmatic; (ii) related to the complexity of human societies, including their interaction with water; and (iii) encompass a set of theoretical difficulties that also arise in systems subject to Darwinian evolution - a state-dependence of the underlying "rules" that govern system change (analogous to change of model structure) known as self-reference.

Numerous pragmatic challenges arise when attempting to understand human-water interactions. For instance, quantification of the role or value of water in different social-economic (Olmstead et al., 2007; Harou et al., 2009; Characklis et al., 2006), or socio-ecological settings (Schroter et al., 2005; Suen and Eheart, 2006; Bekele and Nicklow, 2005; Poff et al., 2010) is non-trivial. The different methods, scales, institutions and legal frameworks by which societies around the world manage water (Gleick and Palaniappan, 2010; Röckstrom et al., 2009) generate tremendous specificity in water systems, while variation in norms and cultural practices leads to a diversity of water management behavior. Access to water ranges from largely uncontrolled (Lal, 2005, 2011; Srinivasan et al., 2010a, b); to controlled but decentralized (Tanaka et al., 2006), to centralized and highly controlled (Coulibaly et al., 2001).

Partly as a result of this specificity, the dynamics of the resulting systems are inherently complex. Although the availability of water resources must feed back upon society, the manifestations of this feedback vary strikingly, depending on the wealth of societies (Vörösmarty et al., 2010), legal frameworks (Feldman, 2009), institutional involvement (Ostrom, 2009), global trade (Suweis et al., 2011; D’Odorico et al., 2010; Seekell et al., 2011), stewardship of local resources (Jewitt, 2002) and probably more. Feedbacks are weakened by technological interventions (Brown and Lall, 2006). For example, pre-industrial societies living in floodplains were directly and negatively impacted by flooding and avulsions, which may have caused the abandonment of cities in the Indus Valley and Middle East (An Heyvaert and Baeteman, 2008; Schuldenrein et al., 2004). Contemporary industrial societies, however, persist in floodplains despite periodic destructive events (Di Baldassarre et al., 2009), using technological (e.g., levees) and economic (e.g., insurance) mechanisms to militate against flooding. These mechanisms weaken the coupling between hydrological and societal dynamics, at the expense of amplifying the impact of extreme events when these mechanisms fail. In the USA this was tragically illustrated by failure of levees in New Orleans (Kates et al., 2006), and remains a risk in, e.g., the San Joaquin-Sacramento Delta (Burton and Cutter, 2008). The increased non-linearity of the interaction is characteristic of weak couplings, and seems to be a generic outcome of interactions between society and hydrologic systems (Sivapalan et al., 2012). The risk of such non-linearities is likely to increase in the context of non-stationarity, creating the potential for threshold or "black swan" phenomena (Taleb,
2007) outside the observed range of variability (Kumar, 2011).

While complex, these kinds of non-linear dynamics can be reproduced in models and understood through conventional theory. Yet the success of modern physics in making predictions about complex physical systems has not been replicated in biological and social systems. In a discussion of how to extend concepts from statistical mechanics to Darwinian evolution, Goldenfeld and Woese (2011) hypothesized that the core of this problem lies in the self-referential nature of the evolutionary process. By this, they mean that the set of "rules" or governing equations that describe the dynamics of a system depend upon the system's state. In the case of Darwinian evolution, the system in question is the genome and its environment. Human societies, and their interactions with water, are also self-referential. For example, the legal framework surrounding human use of water often constrains water balance partitioning. Yet, via human agency, this legal framework also changes in response to the management outcomes. Similar changes in norms and values also appear to reflect the context of local water systems (Wutich et al., 2013). In evolutionary biology, self-reference occurs with respect to reproductive fitness as a goal function. In human societies, the goal functions relate to a suite of desired outcomes for the water system, which change based on cultural and social mores, as well as increased understanding of system dynamics (Kandasamy et al., 2013). Self-reference leads to very different trajectories of development for apparently similar physical/environmental situations. For example, Feldman (2009) analyzed the history of the development of water supply in Los Angeles and Atlanta, two large cities with a similar development history, with both having experienced significant water supply limitations. In the 1920s Los Angeles expanded its supply network, draining Owens Lake and deferring demand management until later in its development history. Encountering similar supply limitations for the first time in 2009, Atlanta also sought to expand its water supply, but was prevented by limits in regional water transfers and the Endangered Species Act (Congress of the United States, 1966) which had passed in the interim. The "governing equations" describing how cities appropriate water in the USA changed between the 1920s and 1960s, causing the water history of the two cities to diverge. Despite the complexity of self-referential systems, they have been explored via numerical simulations in the context of, e.g., protein evolution (Earl and Deem, 2004). Similar approaches may be appropriate for exploring human-environmental interactions. While human behavior and decision-making itself may in fact be genuinely unpredictable in many contexts (Dessai et al., 2009; Kasprzyk et al., 2013; Lempert, 2002; National Research Council, 2009), the current situation - where there have been limited studies exploring human-hydrologic feedbacks in a focused manner - can only be improved by developing and synthesizing knowledge around this critical topic. 


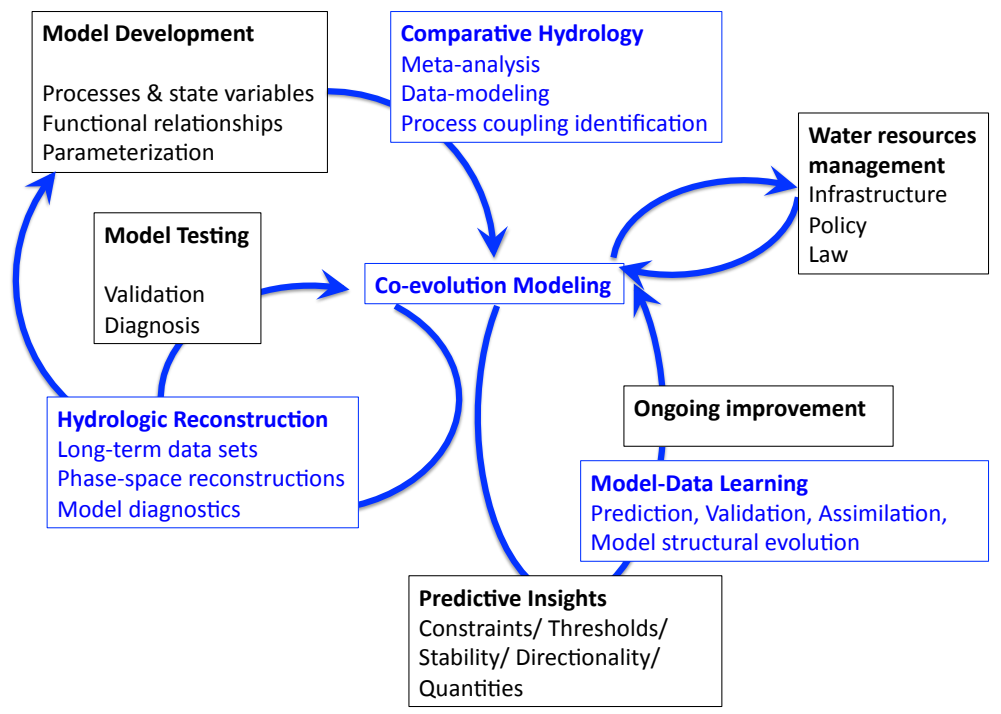

Fig. 2. Components of the proposed research agenda to develop predictive insight over $100 \mathrm{yr}$ time frames in non-stationary water systems.

\section{A research agenda}

We have argued that hydrological science faces a fundamental challenge of obtaining predictive insight on decadalto century timescales that match the timescales on which the effects of water resources management decisions persist. Gaining such insight is contingent on formulating predictive frameworks. These frameworks will differ from conventional hydrological models in that they must account for the interactions between hydrologic and multiple other environmental subsystems (e.g., vegetation cover, pedology, landscape evolution, biogeochemistry, land use dynamics, anthropogenic water demands etc.), in the presence of persistent change in climatic forcing and land use. We refer to these frameworks as co-evolutionary models. Developing co-evolutionary models forms the lynchpin of a research agenda to address predictions about non-stationary systems, as shown in Fig. 2. Co-evolutionary models are necessary tools for making predictions and evaluating water resource management options. The goal of developing, validating, using and improving these models provides a framework for other research activities.

We propose two elements of a research agenda that contribute to the development of co-evolutionary models. The first of these is hydrologic reconstruction, which aims to generate long-term data sets (on the order of 100s of years) encompassing hydrologic, climatic, land use, human, ecological and geomorphologic data, ideally at the watershed/riverbasin scales at which questions of management become most pertinent. Long-term data sets that address both hydrologic variability and the variability in potentially interconnected environmental subsystems provide a basis for identifying and quantifying feedbacks - critical for developing co-evolutionary models. In particular, research efforts that address changes in human-water interactions should be included in reconstruction, so that a basis for exploring human-hydrologic feedbacks on long timescales can be developed. These data sets will also facilitate testing, falsification and improvement of co-evolutionary models. Together, co-evolutionary modeling and hydrologic reconstruction begin to address the major challenges to prediction posed by non-stationarity, while hydrologic reconstruction also provides a basis for the identification, description and parameterization of feedback mechanisms. These feedback mechanisms can also be identified via comparative hydrology, which uses diverse observations of a large population of sites to infer the existence and nature of process interactions and their outcomes. Comparative hydrology creates opportunities for validation and testing of co-evolutionary models by confronting them with data sets from multiple locations, across gradients of social, climatic or ecological variations. By superseding the specificities of individual places or case studies, comparative hydrology will also help the identification of common features and the development of general prediction methodologies. By incorporating different features of human-water interactions into comparative hydrological studies, they also provide a mechanism to address some of the challenges posed by human interaction with hydrologic systems.

The final component of the research agenda addresses the use of co-evolutionary models, recognizing the challenges posed by uncertainty and predictability. Through model-data learning, we suggest that uncertainty can be assessed by creatively linking observations of non-stationary, human impacted systems and models of these systems. These links include using data modeling and assimilation for short-term forecast improvements, and longer-term programs of diagnosis and evaluation to allow co-evolutionary models to change 
and adapt as new evidence of unanticipated feedbacks, unpredicted human interventions and other sources of error emerge in observations. The data-model learning component of the research activity is essential to address the likelihood that emergent trends in coupled non-stationary systems - particularly those impacted by human activity - are not predictable a priori, but must nevertheless be incorporated into models of the co-evolving water system. These elements of a research agenda are elaborated on below.

\subsection{Co-evolutionary modeling}

Co-evolutionary modeling represents the research effort to describe how change in one component of connected environmental subsystems propagates to the others and ultimately impacts hydrologic behavior (Milly et al., 2008; Vogel, 2011; Vörösmarty et al., 2010). It requires developing quantitative descriptions of the connections between water and other earth surface (Brantley et al., 2006), biological (Poff et al., 2010) and social disciplines (Braden et al., 2009), and propagating these descriptions through time to describe the trajectory of the coupled systems. As such, it requires both extension and synthesis of existing hydrologic modeling techniques. While existing mechanistic hydrologic models can be coupled, through the interdependence of their parameters, to models of other physical or biological systems (Flores et al., 2009; Qu and Duffy, 2007; Tucker et al., 2001; Beven, 2007), and while many existing land surface modeling schemes already link ecological, climatological and hydrological fluxes (Gerten, 2013), indiscriminately extending such complex models rapidly becomes intractable. Thus, other modeling approaches are essential. In particular, an understanding of the dynamics of coupled systems via low-dimensional, non-linear modeling can be used to judiciously focus the development of co-evolutionary models towards the most important processes influencing hydrologic change.

We suggest that research into co-evolution modeling could be structured specifically around the challenges identified with making predictions about coupled systems: (i) identifying, (ii) functionalizing, and (iii) parameterizing process coupling, and coping with the significant theoretical challenges associated with human behavior.

To begin with, data-driven modeling approaches offer an avenue towards the identification of process coupling as revealed in time series records (Abrahart et al., 2012; See et al., 2007; Young, 2013). The information theoretic approach of Ruddell and Kumar is one methodology that can extract signatures of coupling from time series records (Ruddell and Kumar, 2009a, b). Other approaches, such as those developed to identify synchrony and time delays (Quian Quiroga et al., 2002), or causality metrics developed for non-linear systems or time-local systems (Detto et al., 2012; Hatala et al., 2012; Molini et al., 2010) are also appropriate to identify coupling. None of these approaches provides process descriptions or parameterizations, but they generate a suite of diagnostic tools that can be used to identify signatures of coupling from observations, guide hypothesis development, and assist with model evaluations. Data availability provides the major constraint on data modeling. Incorporating datadriven approaches within the hydrologic reconstruction activities proposed in Sect. 3.2 could help provide data about coupling with long characteristic timescales, which is likely to be important when considering hydrologic predictions of changing systems. Other approaches for identification of process coupling, such as focused observational studies, remain relevant; but an expansion of data-driven approaches would capitalize on recent theoretical developments and the large quantities of information about process coupling that must reside within existing data sets.

Having identified the existence of process coupling, quantitative descriptions of the feedbacks between systems may be inferred from time series data or from targeted observations of the process interactions. At this point, a second class of modeling becomes valuable: low dimensional models targeted at understanding system dynamics (Koutsoyiannis, 2010). Such "toy models" - based on simple coupled ODEs/PDEs or cellular automata, and often relying on simplified representations of lumped physical processes - parsimoniously represent the feedbacks and nonlinearities that drive co-evolutionary relationships, remaining simple enough to allow analytical exploration, deployment in stochastic frameworks without requiring large computing infrastructure, and accessibility (Kumar, 2011). These kinds of models have been successfully used to predict threshold-like transitions in ecology - for example between oligotrophic and eutrophic conditions in shallow lakes (Dent et al., 2002; Scheffer et al., 2001), vegetated and desertified conditions in semi-arid shrublands (Kefi et al., 2007; Rietkerk et al., 2002), between grass- or shrub-dominated semi-arid rangelands (D'Odorico et al., 2006; Okin et al., 2009), or even between conditions in which mussel colonies can or cannot establish (van de Koppel et al., 2005). Efforts in resource economics have demonstrated that low-dimensional models that couple human and natural systems can have significant explanatory power (Taylor and Brander, 1998), for example, by interpreting the specific interactions and conditions that explain the collapse of the monument-building culture on Easter Island (Fig. 3). In hydrology, these models could help identify the different "regimes" of hydrological behavior that can arise in hydrologic systems as a function of climatic, geologic or other control parameters; could indicate the potential for thresholds or locally irreversible transitions to arise in hydrologic systems; or for helping to identify warning signs of changes (Scheffer et al., 2009; Wolff, 1990; Dakos et al., 2008). They could also (critically) identify process couplings that are relatively unimportant for non-linear transitions or changes in processes, and as such provide a rationalization for simplifying the scope of modeling activities. Of course these models also have limitations: for instance it 

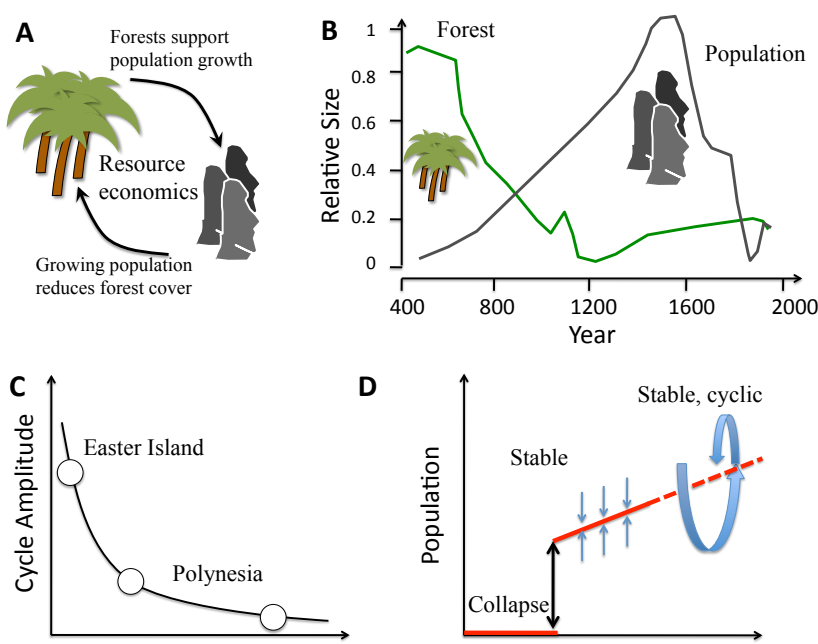

Forest Growth Rate

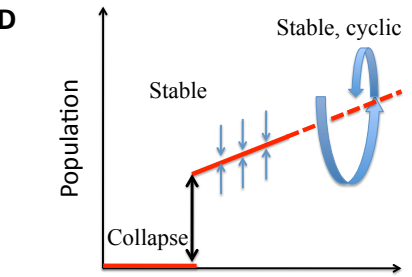

Birth Rate

Fig. 3. Illustration of the potential value of minimal non-linear models to interpret interactions between nature and society. This illustration follows the analysis of Taylor and Brander (1998), who considered a resource-economics model of the society on Easter Island, which was dependent on a palm forest resource (A). Archaeological evidence illustrates the interaction of this forest resource with the human population, which follows a cyclical pattern with varying amplitude, including a large "crash" in human population (B). Similar dynamics are not seen on other Islands in Polynesia, and arose in Easter Island (according to the modeling and biological evidence) because of the unusually slow growth rates of the palm trees (C). Simple models can make predictions about complex system behavior - for instance as a function of the birth rate (and other control parameters), the long-term dynamics of this system tend to either complete collapse (explaining, perhaps the 12 "mystery" islands of Polynesia which were once colonized but ultimately abandoned), a simple approach to a stable population through time or a complex approach to a stable population via limit cycles with variable amplitude.

is challenging to use these low dimensional frameworks as a basis for making detailed predictions in a distributed fashion, and the simplifications and lumped representations of fundamental processes often demand that modelers make decisions about which processes to include and which to exclude, decisions to which the models can become very sensitive. Developing low- and high-dimensional models in such a way that they can be tested against each other and against observations might facilitate the creation of a suite of tools that can span different orders of complexity (see Sect. 4.2).

Ultimately, we will wish to use detailed mechanistic (bottom up) models of coupled systems to generate quantitative predictive insights. Several such models already exist for different eco-hydrological, hydro-geomorphological and other applications (Flores et al., 2009; Qu and Duffy, 2007; Tucker et al., 2001). It is unclear, however, whether existing models are well prepared to cope with non-stationary systems (Wagener et al., 2010). Testing these models with

data sets developedthrough hydrologic reconstruction provides one way to evaluate their performance under changing conditions. An alternative approach would be to apply modeling frameworks to contemporary locations experiencing significant imposed change. These tests would aim to "push" the parameterizations and process representations of existing models beyond the phase-space defined by stationary conditions. The performance of the models experiencing such a push would provide a basis to consider future refinements, which could, e.g., consider new process interactions identified from data modeling and shown to change system dynamics through dynamical systems arguments.

A final element of co-evolutionary modeling that requires special consideration is the challenge of incorporating the role of people into predictive frameworks. As discussed in Sect. 2.4, there are fundamental theoretical challenges associated with this synthesis of hydrologic and socio-economic issues. Self-reference, complexity, weakly coupled systems and the potential for genuine unpredictability are new challenges for hydrologists - and some of them remain novel challenges for mathematicians, economists and theoretical physicists. Incorporating metrics of human-water interaction into comparative hydrologic studies and reconstruction efforts provides a partial response to this challenge. Developing models that describe human-water interactions and determining if these have explanatory power (as per, e.g., Di Baldassarre et al., 2013) also offers a partial response. None of these approaches, however, are likely to be sufficient to fully address the theoretical complexity raised by the particular features of human-water interactions. The final component of the co-evolutionary modeling exercise must thus be to progress with fundamental theoretical studies that shed insight into the behavior of complex, self-referential systems with weak coupling, and potentially unpredictable agents. This is a challenge particularly appropriate to the new science of socio-hydrology (Di Baldassarre et al., 2013), and suggests that this is a discipline in which mathematicians and theoretical physicists, as well as hydrologists and social scientists, may need to be involved (Sivapalan et al., 2012).

\subsection{Hydrologic reconstruction}

Lack of understanding, description and modeling of coevolving coupled hydrologic systems over long time frames poses a major impediment to the formulation and testing of co-evolutionary models to address hydrologic change: for this reason studies of co-evolution on hundred year time frames are a priority. Hydrologists have already attempted empirical reconstructions of hydrological change and water system histories in specific locations, generally motivated by the need to understand the genesis of contemporary hydrological problems (An Heyvaert and Baeteman, 2008; Brazdil and Kundzewicz, 2006; Brazdil et al., 2006; Merritts et al., 2011; Nicholson, 1979; Schuldenrein et al., 2004). While empirically informative, these studies could also provide 

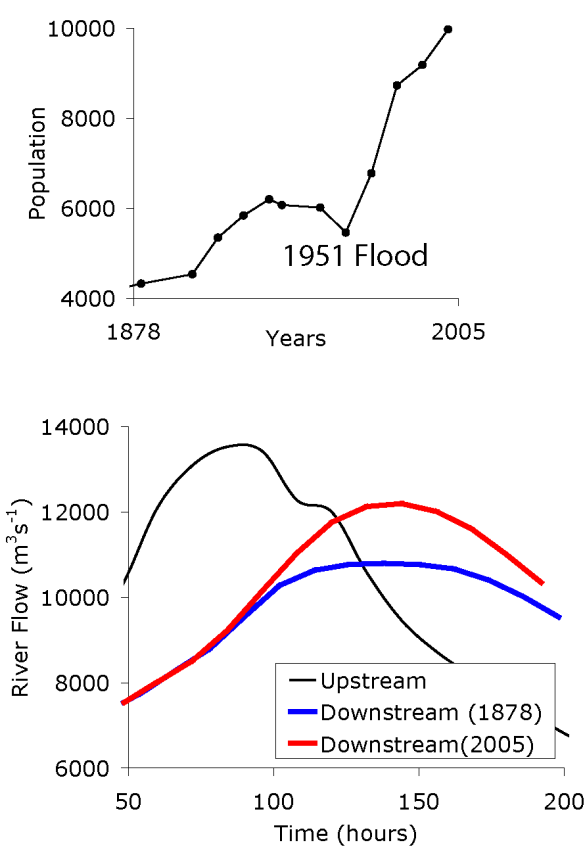
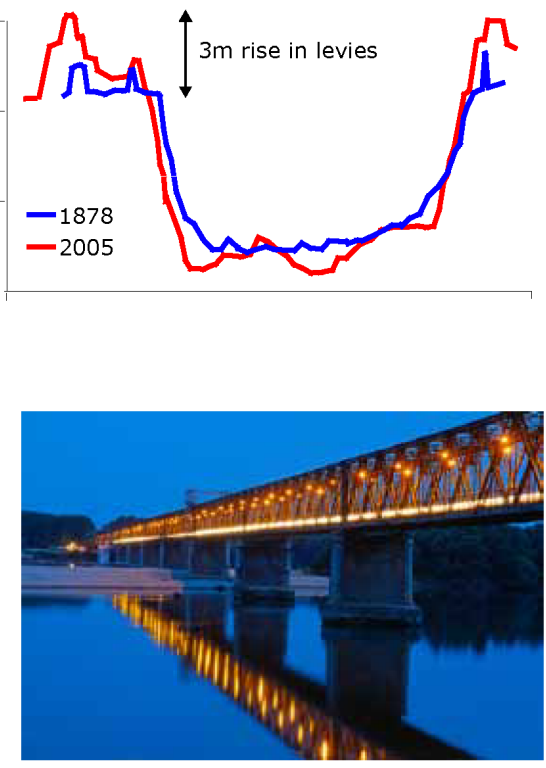

Fig. 4. A simple illustration of hydrologic reconstruction from this issue (Di Baldassarre et al., 2013): as societies develop in floodplains they modify the floodplain to alter the risk of flooding. In doing so, however, flow behavior within the floodplains change, altering the severity of specific events. Data shown are for the Pontelagoscuro region on the Po River, Italy.

valuable theoretical test beds for co-evolutionary models over decadal- to century-scale time frames. In this respect, we take inspiration from climate scientists and paleohydrologists who have benefitted extensively from reconstruction studies (Ganopolski et al., 1998; Lean et al., 1995; Mann and Rutherford, 2002; Nicholson, 1979), which attempt to infer the trajectories of historical (and deep-time) climates, and to reproduce and explain their features via predictive frameworks (Bell et al., 2003; Nicholson, 1979; Smerdon, 2012). Climate reconstruction has provided historical insights (McCormick, 2011); long-term data records that can be used as an empirical baseline against which to compare contemporary changes (Mann and Rutherford, 2002); and opportunities to compare model predictions to empirical (or at least semi-empirical) data over millennial timescales (Bell et al., 2003; Hargreaves et al., 2011).

These reconstruction efforts in climate sciences provide a template for an effort in hydrologic reconstruction, which might be anticipated to provide the same benefits to hydrologists analyzing changing systems: namely (i) the generation of baseline data against which to evaluate contemporary changes; (ii) analysis of natural variability and longterm cycles affecting hydrological systems (Markonis and Koutsoyiannis, 2013; Montanari, 2012); (iii) investigation of hydrological influence on human societies in historical contexts (Brown, 2009; Endreny and Diemont, 2012; French et al., 2012); (iv) evaluation of the nature and magnitude of changes that have been imposed on basins over pre-historical and historical timescales, and assessment of the sensitivity and response of hydrological systems to these changes; and (v) generation of data sets against which to evaluate and improve models of hydrological systems over timescales that exceed the length of the instrumented record.

Hydrologic reconstruction can draw on the methodologies developed for historical and paleo-hydrological studies, whether geological proxies such as lake levels (Lowry and Morrill, 2011; Steinman et al., 2010; Bradley et al., 2010; Nunnery et al., 2010; Luo et al., 2013) or historical documentation such as taxation records (Brazdil et al., 2012). Historical hydrology has used historical experiences to inform risk assessment and to contextualize the present hydrology (Brazdil et al., 2006, 2012; Brazdil and Kundzewicz, 2006; Montanari, 2012), and provides a logical starting point for reconstruction efforts, which would focus on identifying and attributing hydrologic changes in historical data sets. An example of such a research perspective is provided by Di Baldassarre et al. (2013) who interpret changes in flood severity on the Po River (Fig. 4) in terms of levy construction and urban population. Wescoat Jr. (2013) provides a very different example of reconstruction that focuses primarily on the evolution of different water values over time, as embedded in the definition of "water duty" or irrigation needs.

The empirical aspects of hydrologic reconstruction pose clear challenges. Historical records suitable for historical hydrology are not globally available, perhaps explaining an initial bias in these studies towards European catchments (Brazdil and Kundzewicz, 2006). The value of "typical" paleo-hydrological proxies (Baker et al., 1993; Jarrett, 1991) 
for evaluating century-scale changes in watersheds is not well understood. Accessing the hydrologically relevant information embedded in historical data sets - for instance information regarding construction of run-of-river dams for mill operation in the USA (Merritts et al., 2011; Walter and Merritts, 2008) - is likely to require interdisciplinary research, methods for fusing "hard" and "soft" data, and ways to address the reliability of information derived from "human sensors" (Hall et al., 2010).

The predictive aspects of hydrological reconstruction raise questions about pragmatic methods for running and evaluating co-evolutionary models, particularly in their infancy (Milly et al., 2008). For instance, change in these models may be imposed as non-stationarity in parameters; or it could be explicitly modeled through mechanistic representations; or it could drive a non-stationary model structure. The simplest initial strategy may be to begin by evaluating the ability of widely used models to reproduce observed changes when change is captured by non-stationary values of model parameters. Mechanistic complexity and full coupling between different processes could then be added into predictive frameworks as motivated by the model performance - a "top down" approach that broadly mimics the trajectory of climate model development (Edwards, 2011; Sivapalan et al., 2003).

Reconstruction efforts can begin by focusing on existing, empirically well-documented examples of hydrological change such as the drying of the Aral Sea (Micklin, 1988), the genesis of dryland salinity (Clarke et al., 2002) or nitrogen fluxes from the Mississippi (Turner et al., 2008). Focusing on these problems would capitalize on the significant empirical efforts that have already been invested in understanding them, as well as generating useful quantitative tools for their analysis. Future reconstruction efforts could concentrate on basins that are identified as facing significant threats due to climate change and population growth (Vörösmarty et al., 2000, 2010), that offer particular modeling challenges, or which experience non-stationarity in different ways (e.g., changes in precipitation regimes, water abstraction, sea level rise, or land use change).

\subsection{Comparative hydrology}

Comparative hydrology can be used to identify or test hypotheses about trends in hydrological behavior as a function of climatic and/or watershed properties. Comparative hydrology supersedes case study or watershed-specific approaches to hydrologic research, and has the potential to separate sitespecific phenomena from generalizable trends (Falkenmark and Chapman, 1989; McDonnell et al., 2007). With information about hydrological behavior in a large number of watersheds, robust testing of hypotheses generated from comprehensive investigations of a small number of sites (Thompson et al., 2011b) can be generalized via the statistical power of a large data set. Alternatively, statistical and top-down modeling approaches (Sivapalan et al., 2003) applied to many watersheds can be used to identify and explore emergent patterns (Voepel et al., 2011), which can then become targets of hypothesis formation and mechanistic inquiry. These studies can be specifically used to assist in co-evolutionary modeling by targeting them towards identification of feedbacks between hydrologic and other systems.

Comparative hydrology is not a new concept: rather, it is the approach that underpinned Budyko's analyses of hydroclimatology (Budyko and Miller, 1974); Abrahams' investigations of geomorphological features (Abrahams and Ponczynski, 1984), and was formalized in the 1980s by Falkenmark and Chapman (Falkenmark and Chapman, 1989). In recent years, comparative studies have also addressed the classification of vegetation biomes via water balance (Stephenson, 1990, 2003), hydro-climatic controls on NDVI and transpiration (Thompson et al., 2011b; Voepel et al., 2011), controls on hydrologic regimes (Carrillo et al., 2011; Olden et al., 2011; Sawicz et al., 2011), the relationship between available energy and soil development (Pelletier et al., 2013; Rasmussen, 2012; Rasmussen et al., 2011), the implications of different management regimes (Huntjens et al., 2011; Borowski et al., 2008) on water resources, and - in an initial sense - emergent patterns in human-hydrologic interactions (Srinivasan et al., 2012). Figure 5 illustrates three different relationships that emerge from 430 watersheds when considering patterns of hydro-climate (Budyko's curve), geomorphology (Abrahams curve) and vegetation cover (aridity - NDVI curve). Research that uses these emergent relationships as a constraint has provided insight into catchment processes (Brooks et al., 2011; Troch et al., 2009), while empirically these patterns provide a minimal basis for prediction and extrapolation (Zhang et al., 2001, 2008). Comparative hydrology recently formed the basis for a comprehensive synthesis (across processes, places and scales) of runoff prediction model performance, undertaken as part of the Predictions in Ungauged Basins (PUB) initiative (Blöschl et al., 2013; Hrachowitz et al., 2013).

Although comparative hydrology is an existing technique, there is potential to expand its application and orient it specifically towards changing or anthropogenically impacted water systems. Comparative hydrology offers a way to identify hydrologic responses to imposed change and the modes by which these responses occur. Intercomparison of watersheds experiencing similar trends in warming, drying or changing rainfall patterns may reveal commonalities in terms of bulk hydrological responses (Wagener and Montanari, 2011), and longer-term watershed evolution, perhaps manifested in ways that are readily detectable by remote sensing, such as vegetation cover or land use. Such "data-mining" approaches may prove to be the best way to begin understanding the diversity of responses of complex systems to exogenous forcing, when theory does not immediately offer a clear prediction. Subdivision of large data sets into training and prediction groups provides one approach that facilitates testing, falsification and improvement of hypotheses generated 
Mopex Catchments

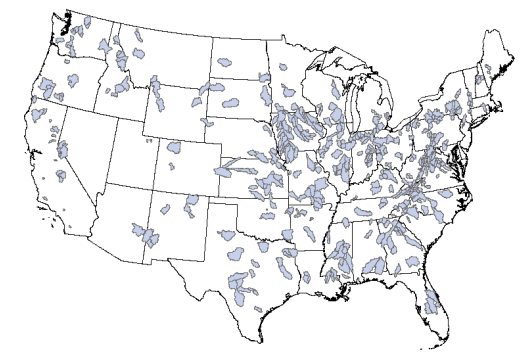

Budyko Curve

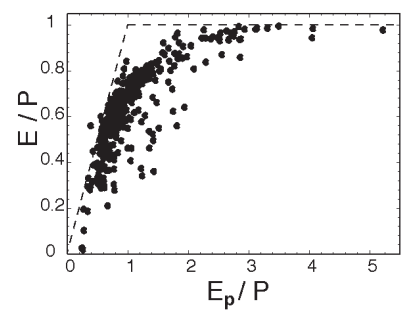

Abrahams Curve

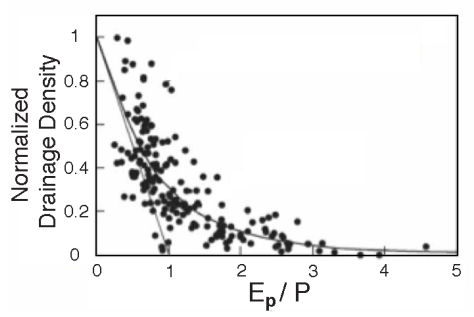

US Vegetation Cover

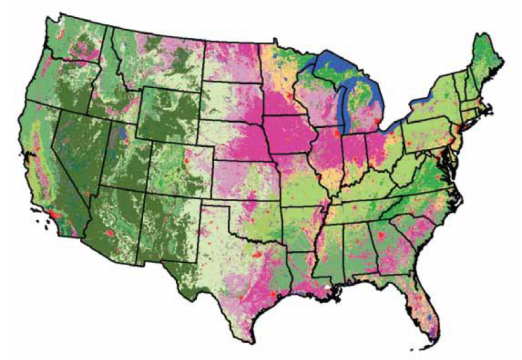

NDVI Trends

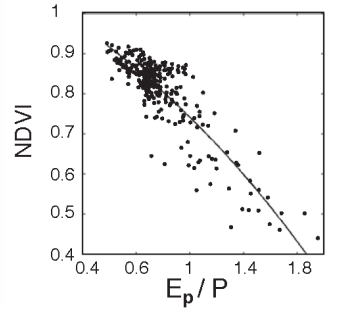

Fig. 5. Illustration of three studies in comparative hydrology: Budyko's curve provides constraints on the hydroclimatic regime of individual catchments with a typical relationship emerging between aridity (potential evaporation normalized by precipitation) and the catchment evaporative fraction. Here it is reproduced from data from 430 MOPEX catchments across the USA (Budyko and Miller, 1974; Duan et al., 2006). Abrahams curve indicates a typical relationship between the drainage density in a catchment and aridity, here again MOPEX data have been used to derive the curve (Wang and Wu, 2013). Finally, vegetation greenness, as measured by NDVI, also follows characteristic patterns with aridity (Voepel et al., 2011).

through these methods. Alternatively, methodological explanations for emergent patterns can be sought, and used to formulate new predictions about the nature of change in unobserved aspects of the study watersheds (Wagener, 2007). These new predictions then form a target for hypothesis testing and improvement.

Secondly, comparative hydrology offers a test bed for hypothesis and theoretical evaluation, and model validation. Theories that are robust to changes in climate and land use should be valid across gradients of watershed properties as manifested by individual places (Beven, 2000). Comparative hydrology facilitates space-for-time substitution along gradients of climatic, geological or land use properties. The breadth and diversity of human societies can and should also be represented in comparative hydrologic studies, to allow emergent patterns that may primarily reflect socio-economic drivers, and variations in cultural norms, values and behavior with respect to water to be elucidated. There is currently a bias towards large numbers of observations in North America and Europe, with fewer observations available at a global level: addressing this disparity through targeted international data gathering and sharing is a core need.

Thirdly, and pragmatically, comparative investigations that treat watersheds as the unit of inquiry generate findings at the spatial scale relevant to management and decisionmaking. Thus, comparative hydrology can help to circumvent the extrapolation challenges implicit when generalizing high-resolution studies to regional scales, and offers a holistic analytical method in contrast to reductionist approaches that may become intractable at large spatio-temporal scales (Killeen and Abrajano, 2008).

Identifying an appropriate metric by which to evaluate hydrologic behavior across watersheds is critical to comparative hydrology. Previously studies have successfully used signatures of the hydrologic regime, such as annual water balance partitioning (Budyko and Miller, 1974), or the flow duration curve (Vogel and Fennessey, 1994, 1995), or several of these signatures together (Blöschl et al., 2013). Signatures of hydrologic change, as well as methods to detect such change are needed to apply comparative hydrology to changing watersheds. Over long timescales, hydrologic proxies drawn from dendro-chronology or paleo-hydrology may prove useful, and provide the capacity to extend the hydrologic record over long-enough periods to generate statistical power (Margolis et al., 2011; Mundo et al., 2012; Woodhouse et al., 2013; Yang et al., 2012; Baker et al., 1993; Jarrett, 1991). To allow comparative hydrology to provide insight into human-hydrologic relationships, signatures that specifically relate to this interaction over historical and modern time periods must also be identified. Numerous existing data sets collect hydrological data within reasonably wellcharacterized ecological, geological and climatic contexts. Extending these approaches to incorporate socio-economic data from censuses, surveys and economic records will be 


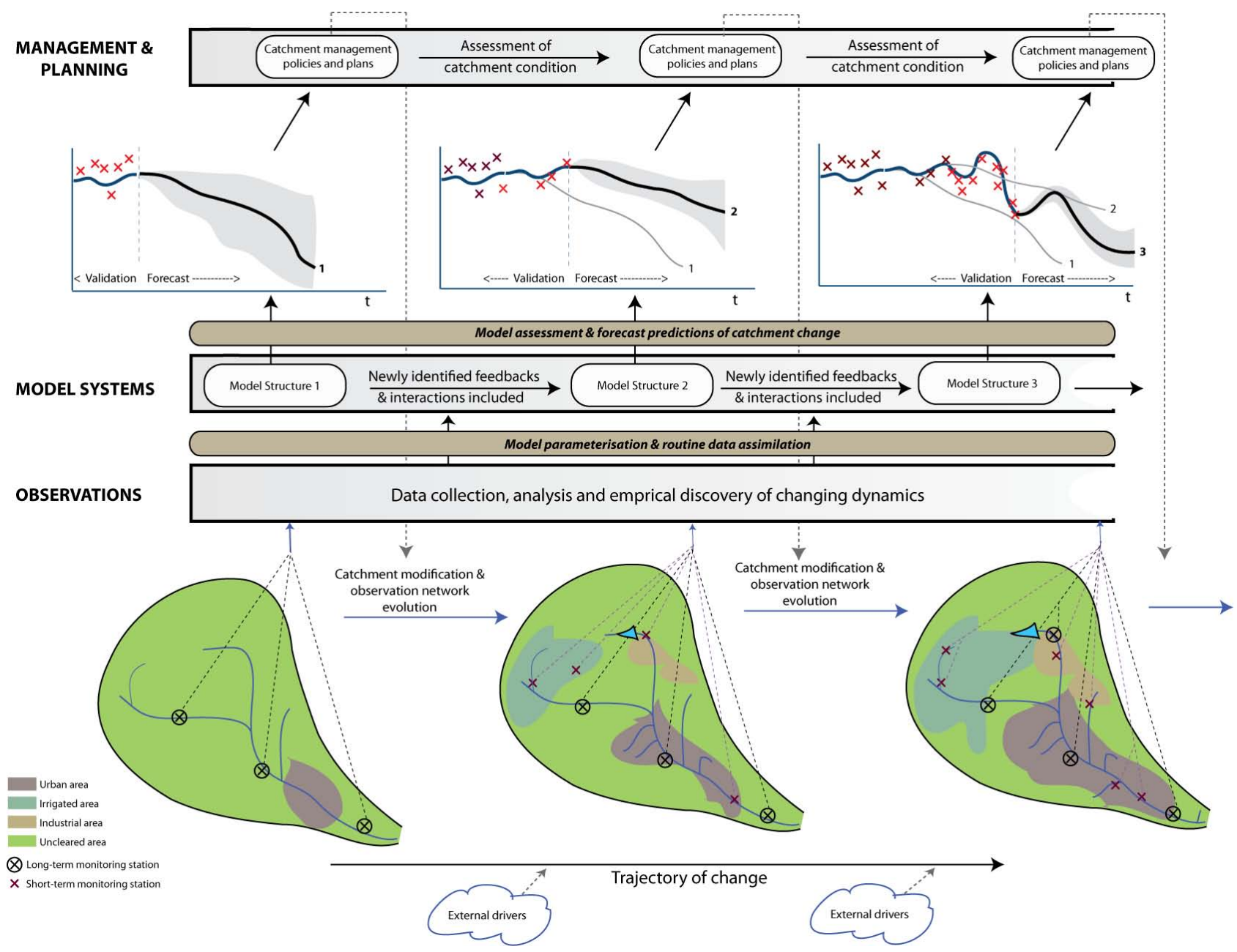

Fig. 6. Conceptual illustration of how model-data fusion could be built into a use-based science paradigm incorporating scientists, managers and the community for real-time management of water systems. The diagram highlights a system whereby (a) model uncertainty reduces over successive iterations of model development, (b) the model's ability to reproduce new dynamics evolves as model structures improve, motivated by new learning from observations, and (c) the observation network adapts in response to changing land-use and management priorities.

critical for consideration of change in managed watersheds (Haberl et al., 2006; Redman et al., 2004): fusing hydrological and socio-economic data sets productively will require interdisciplinary efforts.

\subsection{Model-data learning}

Model-data learning refers to the synthesis of models and observations for short-term prediction (for the purposes of reducing uncertainty for prediction in engineering and management control, "Type F" predictions according to Kumar, 2011) and long-term adaptation of the predictive frameworks to account for the effects of un-represented, unpredicted or unanticipated change in hydrologic systems (for the purposes of identifying novel phenomena, "Type N" predictions; Kumar, 2011). There are several ways in which modeldata learning can support improved predictions in changing systems: (i) reduction of uncertainty in short-term forecasts; (ii) as a means for identifying model weaknesses in reproducing essential system-level dynamics of change and updating model structures or approaches as the system of interest undergoes change; (iii) by identifying deviations from expected system behavior which may be attributable to previously undetected feedback mechanisms; and (iv) by updating observation networks through time to maximize the value of the observations for prediction. We illustrate the relationship of these activities to prediction and to each other in Fig. 6.

The "short-term" mode of model-data fusion relies upon using observations to correct predictions made by uncertain models. Given the inherent limitations of both observations and models in describing the "true" states and dynamics of systems, this combination will be facilitated by the use of Bayesian frameworks that can extract useful 
information while simultaneously acknowledging these limitations (e.g., Drécourt et al., 2006; Kollat and Reed, 2008; Gupta et al., 2008; McLaughlin, 2002; Haimes, 1979). The ability to unambiguously identify optimal model structures or parameter sets via observation, however, remains highly constrained (Neuman, 2002; Beven, 2006a; Langbein, 1979; Moss, 1979a; Dooge, 1986). These constraints may be alleviated in part by exploring new kinds of observations or metrics to use in model analysis. For instance, model predictions could be conditioned on diagnostic metrics that evaluate catchment function, hydrologic signatures or systemscale emergent relationships. Examples of such emergent features might include connectivity metrics between catchment and hillslope, or patterns of connection across nodes in a complex network (Jencso et al., 2009, 2010; Ruddell and Kumar, 2009a, b). The scope to improve model predictions by improving model representation of processes - rather than reproduction of single-state variables - remains incompletely explored. Novel, data-driven approaches towards constraining model error on short timescales - for instance by applying machine-learning approaches to interpret systematic model errors and filter them out in future prediction steps - may also have value for improving short-term predictions in changing systems, when models have not yet adjusted to keep up.

Over longer timescales, of course, changing hydrologic systems demand that model structures as well as model parameters should change to reflect new dynamics. Model changes must be based upon identification of poor model predictability, and deliberate efforts to address it (Beven, 2007). Model-data confrontation provides the best basis for identification of error; and the information provided by these confrontations will likely improve when using multiple, theoretically relevant metrics of model performance to document the divergence of simulated and observed catchment responses to change. Dedicated investigation (informed by analysis of model errors) can then target these areas and improvements. Contemporary techniques for addressing model structural error all involve elements of model intercomparison and expert assessment (Refsgaard et al., 2006).

It is also possible to imagine model changes arising through combinations of multiple models, and an automated machine-learning approach to selecting the optimal model combination based on data updates. In effect, model structure itself then becomes a target for assimilation approaches. The learning systems component of such a framework has the potential to advance rapidly given developments in cyberinfrastructure and computational techniques for data analysis and hydro-informatics (Beck, 2010; Hanson, 2007; Porter et al., 2009; Solomatine and Ostfeld, 2008).

The final benefit of model-data fusion for making predictions in changing hydrological systems lies in optimizing observations of these systems for detection of novel dynamics (and thus identification of feedbacks), and also improvement of predictive strategies. Environmental change should not only drive adaptation of hydrologic models, but also of hydrologic observational strategies (Reed et al., 2006). At present our national, regional, and local observation strategies are largely ad-hoc, non-adaptive, aligned towards understanding status quo behaviors (rather than changing systems) and disconnected from evolving water resources policy and management needs (Davis et al., 1979; Moss, 1979b; Langbein, 1979; United States Geological Survey, 1999; Kaushal et al., 2010; Lindenmayer and Likens, 2009). As a result there is incongruence between water resources prediction needs and their support from existing observation networks. Adaptive observation networks could enable us to transition hydrology towards real-time learning. By coupling model learning and observation strategies, we can envisage a systematic feedback between observation, investigation, prediction and management under continuously changing conditions (Reed et al., 2006).

\section{Organizing framework for proposed research agenda}

The implementation of the research agenda proposed in the last section raises major organizational challenges. Global water problems demand urgent input from the hydrologic community: and yet the value of this input is contingent on continuing improvements in the fundamental scientific understanding of complex water systems. The first organizational challenge, therefore, is for hydrologic research to produce science with applications to water management problems while simultaneously maintaining progress in fundamental water science (Dunne et al., 1998; Stokes, 1997; Torgersen, 2006). Next, many features of the proposed agenda, including its increasingly interdisciplinary focus; the ambitious proposals for long-term data-model learning; and the need to gather, interpret and share large data sets to facilitate comparative hydrology and reconstruction; suggest scientific tasks that lie beyond the scope of individual researchers, but instead require interdisciplinary science teams, along with the infrastructure to support their work.

The proposed organizational framework for implementing the research agenda therefore invokes (i) use-inspired basic science, also known as "Pasteur's Quadrant", and which incorporates discovery-driven, individual science (Stokes, 1997), and (ii) "big or team science" (Torgersen, 2006; Borner et al., 2005; Hall et al., 2008; Stokols et al., 2008), both of which pose their own challenges, including financial support and coordination, nationally and globally. In this section we outline some of the activities and products that could support this research framework.

\subsection{Use-inspired basic science to study hydrologic change}

Use-inspired basic science is an approach that attempts to frame pure science problems within the framework of the 
Table 1. Links between some anticipated trends in hydrologic drivers, the water problems that these trends are likely to cause, and the cascade of secondary effects that are generated over a long time frame. Science questions that result from these problems are framed in broad terms, and largely relate to emergent features of water systems.

\begin{tabular}{|c|c|c|c|}
\hline $\begin{array}{l}100 \mathrm{yr} \text { trends } \\
\text { (anticipated) }\end{array}$ & $\begin{array}{l}\text { Resulting water } \\
\text { problems }\end{array}$ & Secondary effects & Science needs \\
\hline $\begin{array}{l}\text { Changing demography } \\
\text { (population size and } \\
\text { lifestyle) }\end{array}$ & $\begin{array}{l}\text { - Water demand } \\
\text { - Food demand } \\
\text { - Energy demand }\end{array}$ & $\begin{array}{l}\text { - Infrastructure } \\
\text { - Technology } \\
\text { - Land use change } \\
\text { - Development of real and virtual water } \\
\text { markets } \\
\text { - Attitudes, policy, law }\end{array}$ & $\begin{array}{l}\text { - Define spatio-temporal dynamics of } \\
\text { water supply, demand and water } \\
\text { stress }\end{array}$ \\
\hline $\begin{array}{l}\text { Urbanization of } \\
\text { population }\end{array}$ & $\begin{array}{l}\text { - Urban modification of } \\
\text { hydro-climatology } \\
\text { - Resource demands } \\
\text { - Water transfers } \\
\text { between urban area } \\
\text { and its region }\end{array}$ & $\begin{array}{l}\text { - Infrastructure } \\
\text { - Technology } \\
\text { - Changes in water quality } \\
\text { - Attitudes, policy, law }\end{array}$ & $\begin{array}{l}\text { - Interaction of urban centers, their } \\
\text { hinterlands and beyond } \\
\text { - Emergent properties of urban } \\
\text { centers, their water infrastructure } \\
\text { and resulting hydrology and } \\
\text { climatology } \\
\text { - Valuation of ecosystem services }\end{array}$ \\
\hline Warming climate* & $\begin{array}{l}\text { - Reduced snowpack } \\
\text { storage } \\
\text { - Increased evaporative } \\
\text { demand }\end{array}$ & $\begin{array}{l}\text { - Changing agriculture, land use, } \\
\text { vegetation }\end{array}$ & $\begin{array}{l}\text { - How does changing temperature } \\
\text { alter water budget partitioning, } \\
\text { supply and demand? } \\
\text { - Ecohydrological and } \\
\text { biogeochemical transition }\end{array}$ \\
\hline $\begin{array}{l}\text { Changing rainfall } \\
\text { variability }\end{array}$ & $\begin{array}{l}\text { - Flood risk } \\
\text { - Supply shortfalls }\end{array}$ & $\begin{array}{l}\text { - Infrastructure development to militate } \\
\text { against extremes (e.g., desalination) } \\
\text { - Changing agriculture, land use, } \\
\text { vegetation }\end{array}$ & $\begin{array}{l}\text { - How is rainfall variability (including } \\
\text { extremes) propagated into flow, } \\
\text { water balance, water quality, } \\
\text { demand, ecology etc.? }\end{array}$ \\
\hline Rising sea levels & $\begin{array}{l}\text { - Aquifer salinization, } \\
\text { flooding }\end{array}$ & $\begin{array}{l}\text { - Infrastructure } \\
\text { - Attitudes, policy, law }\end{array}$ & $\begin{array}{l}\text { - How are coastal surface and } \\
\text { subsurface water systems } \\
\text { connected to the ocean? }\end{array}$ \\
\hline $\begin{array}{l}\text { Globalization of water } \\
\text { systems }\end{array}$ & $\begin{array}{l}\text { - Interdependence of } \\
\text { water systems } \\
\text { - Increased spatial scale } \\
\text { of water problems }\end{array}$ & $\begin{array}{l}\text { - Land appropriation } \\
\text { Changing agriculture, land use, } \\
\text { - vegetation } \\
\text { - Creation of externalities, globalization of } \\
\text { disparity } \\
\text { - Conflict }\end{array}$ & $\begin{array}{l}\text { - Define spatio-temporal dynamics of } \\
\text { water (and pollution) and virtual } \\
\text { water supply, demand and resulting } \\
\text { stresses }\end{array}$ \\
\hline
\end{tabular}

* Climate change effects are separated into impacts on temperature and rainfall (since rainfall projections are more uncertain). Other modalities of global climate variability (dimming, stilling) may also lead to changing evaporative demand (McVicar et al., 2012a, b).

applications of that science. Elements of use-inspired basic science were invoked in past discussions of hydrologic research orientation, emerging strongly in articulating the research role of the National Laboratories in the USA and other locations, and more recently in the NRC report on the state of hydrologic science (Dooge, 1988; Dunne et al., 1998; Stokes, 1997; National Research Council, 2012). It is proposed here as a way to supersede tensions between fundamental and applied research. We propose two complementary elements of use-inspired science for hydrology: firstly, using "real world", societally relevant problems as motivation for defining pure science questions; and secondly, viewing managed and modified systems as targets and opportunities for fundamental scientific inquiry.

\subsubsection{Motivation from real-world problems}

Use-inspired science - as the name suggests - takes real problems, in this case water sustainability or water management problems - as a starting point. The goal of use-inspired science is not, however, to provide immediate solutions to these problems (Stokes, 1997), but to determine what the fundamental knowledge gaps are that impede or lower the quality of the solutions that are developed. These gaps then become the targets of investigation. In this way, fundamental research can be framed and pursued while maintaining a direct connection to its applications, while research priorities can be linked to management priorities. Table 1 shows how significant water sustainability problems that are likely to arise in response to global trends in the next $100 \mathrm{yr}$ present 
water science questions that represent targets for scientific investigation. Each of these problems generates a cascade of secondary effects that will influence the science questions, illustrating the complexity and coupled nature of the water science that must be invoked to address these problems.

\subsubsection{Managed real-world water systems as targets for scientific understanding}

The second element of use-inspired science that we propose is to recognize that the extent of human appropriation of water supplies means that we need to improve our fundamental understanding of the hydrology of managed and impacted systems. The dichotomy in water science, where researchers focusing on "blue sky" hydrologic research mostly considered natural systems, with managed water systems addressed from a pragmatic standpoint, has led to an underrepresentation of managed water systems as targets of scientific research. A major element of use-inspired hydrologic science is to resolve this dichotomy by treating managed systems as legitimate targets of research.

\subsubsection{Implementation of use-inspired science}

In the face of resource constraints and multifaceted water problems, the selection and prioritization of "uses" that should inspire pure science is a value-laden decision. It requires identifying and framing the hydrological problems embedded in emergent water problems. Because hydrological variability leads to problems that impact people only after the effects of water availability or scarcity are filtered through local social and cultural context, correctly framing the pertinent hydrological science problems is not straightforward. Instead it is intimately related to a host of associated social, cultural and economic processes (Srinivasan et al., 2013). While this poses challenges, this also leads us to suggest that use-inspired science provides an exciting target for sociohydrological research, and for exploring the use of collaborative learning frameworks that link communities, managers and researchers to jointly address resource management problems as a way to inspire fundamental science (Metcalf et al., 2010; Daniels and Walker, 2001; Tidwell and Van Den Brink, 2008). Use-inspired science does not provide a framework for management or for bridging divisions amongst science-policy-users in practice. It does, however, provide an opportunity to orient fundamental scientific research towards pragmatic needs and outcomes.

With these caveats, it is nonetheless possible to envisage a long-term relationship between fundamental science development and managed water systems, illustrated conceptually in Fig. 7. In this model, scientific investigation, model development and management mutually improve each other (Dooge, 1986), with science applications (uses) being integrated into the scientific investigative process. Again, this is not a model for the implementation of water resources

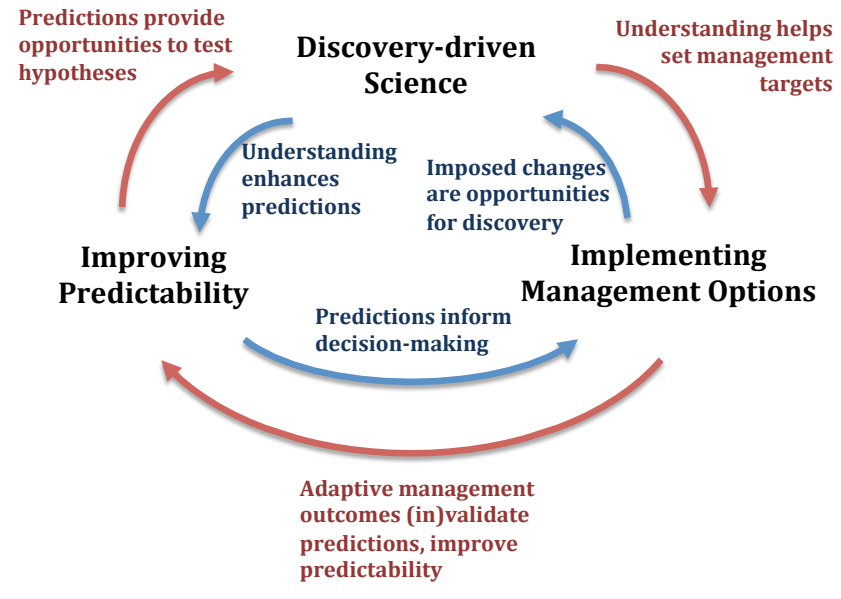

Fig. 7. A conceptual structure for "use-based" hydrology, encompassing management, pragmatic prediction and fundamental science.

management at any particular site, which in practice should incorporate site-specific needs, translational activities tailored to local communities, science questions and policy needs, and a long-term commitment to collaborative development of social and environmental system knowledge. Instead, this diagram is intended to illustrate a broad-scale vision for mutually beneficial relationships between fundamental science and water resources management. Given long timescales of management and evaluation, Fig. 7 would most fruitfully apply to institutional relationships, relating to data collection, sharing, and ongoing prediction and evaluation efforts. Individual investigators could then engage with this process on shorter timescales. The data collected and insights gained would provide a basis for historical reconstruction. Alternatively, comparative studies could explore hydrologic outcomes as legacies of past management actions in multiple settings.

\subsection{Team science to study hydrologic change}

Although many of the activities proposed in the research agenda can be implemented by individual researchers, there is a clear impetus towards addressing the problem of hydrologic predictions through team efforts by supporting both individual and collective ideas. The need for team science arises from the interdisciplinary nature of the problem of change in water systems; from the high levels of cyberinfrastructure needed to implement the vision of modeldata learning; and from the large investments in data generation and sharing that are needed to facilitate reconstruction and comparative studies. Thus, the organizational framework for implementation requires targeted approaches towards team science. Fortunately, many of these needs are highly compatible with the mission statements and goals of existing institutions such as CUAHSI (United States) and 
IAHS (international), and can thus build from consolidation and extension of existing initiatives (Montanari et al., 2013).

\subsubsection{Fostering interdisciplinary teams}

Interdisciplinary engagement is critical for undertaking comparative hydrologic studies, hydrologic reconstruction and formulating modeling frameworks that could account for change. Yet fostering successful interdisciplinary engagement remains a non-trivial challenge (Larson et al., 2011; McGuire, 1999; Morse et al., 2007; Salazar et al., 2012), particularly when team members may be geographically separated. Fostering the creation and success of interdisciplinary teams depends on (i) creating an environment that supports interdisciplinarity, (ii) crafting problems around which teams can focus their efforts, and (iii) access to the tools and infrastructure that can facilitate the activity of these teams. Given the use-inspired science framework, we will add that these teams should also include representatives from the research community in water resources and hydrology, as well as managers and representatives from agencies. Teams can be supported by building on existing mechanisms such as the Research Coordination Networks (RCNs) supported by the US National Science Foundation, which specifically aim to bring disparate communities of knowledge together at national and international levels. Existing forums - e.g., at large international conferences - are available for these groups to promote their ideas and communicate their findings, providing a route to credibility within the field. Working cooperatively between primarily research oriented forums (e.g., AGU, EGU) and forums with a stronger focus on application and management (e.g., EWRI, ASCE) could provide an institutional mechanism for supporting use-inspired science. These mechanisms are simple, low cost, and capitalize on existing momentum towards interdisciplinary science in many research communities. Successful interdisciplinary teams are often centered around an attempt to understand multifaceted, real-world problems (Irwin et al., 2012). Tangible problems and desired outcomes assist in creating common goals, and motivate researchers through the challenging processes of developing common vocabulary, conceptual frameworks and methods (Thompson et al., 2011a). In this way, use-inspired science may also provide a framework for team science.

Given that most interdisciplinary teams are not co-located, common infrastructure, particularly online infrastructure, can also help to foster these teams. The opportunities for developing tools to assist in research are expansive. They range from innovations in database design to facilitate the generation of interdisciplinary data sets, to communications platforms, to online platforms that provide toolkits for specific research tasks. For example, within the climate and atmospheric science community, the online Data Assimilation Research Testbed (DART) supports model-data fusion in a model-neutral fashion (Anderson et al., 2009). By being model-neutral, DART has tremendous flexibility in its applications. It is well supported by staff, training courses, web-resources and a physical presence at UCAR. Institutions such as CUAHSI have a clear interest in similar kinds of infrastructure, and there remains tremendous scope for innovations in this area. Creative uses of online platforms are particularly critical as research becomes more international and interdisciplinary. Critical changes in water systems occur worldwide, but the distribution of research capacity and observations remains strongly skewed towards North America and Europe. There are scientific and ethical imperatives to address these discrepancies, at least by ensuring open access to data sets (as users or contributors) and research platforms. The expertise of international institutions such as the IAHS and UNESCO in promoting international hydrological cooperation can be leveraged to promote equal access to and participation in community-led efforts.

\subsubsection{Collaborating to share data and make observations}

The research activities proposed in Sect. 3 generate a need for data that spans (i) multiple locations, (ii) multiple time frames, and (iii) multiple disciplines (Blöschl, 2006; Paola et al., 2006). Consolidating existing hydrological (and earth science and ecological) data collection and curation efforts (summarized in Table 2) will go a long way towards addressing the first two needs (Hipsey and Arheimer, 2013). The value of such curated and standardized data sets is illustrated by the MOPEX data set which was made public in 2006 and has, since then, resulted in the publication of over 40 diverse comparative studies (Duan et al., 2006). The quality control, core metadata accessibility, and standardized format of the MOPEX data set make this data set highly valuable to hydrologists for comparative hydrology studies. More such data sets are needed, with additional information to support interdisciplinary analysis and over an expanded geographic area. Strategically, many existing observation networks could be leveraged to generate valuable data sets for interdisciplinary hydrology (see Table 2). For instance, the Fluxnet data sets provide unrivalled, high resolution information about evapo-transpiration dynamics, but insufficient soil moisture observations to allow water budget closure (Thompson et al., 2011b). Adding these soil moisture observations would increase the hydrologic value of these sites at a relatively small cost, compared to the costs of the eddy-covariance instrumentation already present. Interdisciplinary observation networks such as the Critical Zone Observatories (CZOs) and National Ecological Observation Network (NEON) are also increasingly focused on human impacts and will include urban locations and regions of rapid land use change. These efforts reflect that funding agencies are increasingly aware of the importance of scientific understanding in human-modified environments, an awareness that will benefit the proposed research activities. 
Table 2. Existing data networks that are relevant to hydrological research.

\begin{tabular}{|c|c|c|}
\hline Data set/network & Agency responsible & Primary focus, references \\
\hline $\begin{array}{l}\text { Critical Zone } \\
\text { Observatories }\end{array}$ & NSF, USA & $\begin{array}{l}\text { Physical processes } \\
\text { (Brantley et al., 2006) }\end{array}$ \\
\hline $\begin{array}{l}\text { Long-Term Ecological } \\
\text { Research }\end{array}$ & NSF, USA & $\begin{array}{l}\text { Ecology } \\
\text { (Kratz et al., 2003) }\end{array}$ \\
\hline $\begin{array}{l}\text { National Ecological } \\
\text { Observatory Network }\end{array}$ & NSF, USA & $\begin{array}{l}\text { Ecology } \\
\text { (Lowman et al., 2009; } \\
\text { Schimel et al., 2007) }\end{array}$ \\
\hline $\begin{array}{l}\text { Global Lake Ecological } \\
\text { Observatory Network }\end{array}$ & & $\begin{array}{l}\text { Lacustrine environments } \\
\text { (Hanson, 2007) }\end{array}$ \\
\hline Fluxnet & DOE, USA & $\begin{array}{l}\text { Land-atmosphere } \\
\text { interaction } \\
\text { (Baldocchi et al., 2001) }\end{array}$ \\
\hline $\begin{array}{l}\text { National Water } \\
\text { Information System }\end{array}$ & USGS, USA & $\begin{array}{l}\text { Hydrology, Water quality } \\
\text { (Goodall et al., 2008) }\end{array}$ \\
\hline $\begin{array}{l}\text { Hydrological } \\
\text { Information } \\
\text { System }\end{array}$ & CUAHSI & $\begin{array}{l}\text { Hydrology } \\
\text { (Hooper et al., 2004) }\end{array}$ \\
\hline EarthCube & NSF, USA & $\begin{array}{l}\text { Earth System Sciences } \\
\text { (Moore et al., 2011) }\end{array}$ \\
\hline HCDN & & $\begin{array}{l}\text { Hydrology } \\
\text { (Lins, 2012) }\end{array}$ \\
\hline MOPEX & & $\begin{array}{l}\text { Hydrology } \\
\text { (Duan et al., 2006) }\end{array}$ \\
\hline HELP & UNESCO & $\begin{array}{l}\text { Hydrology (international) } \\
\text { (van Lanen et al., 2002; } \\
\text { Bonell et al., 2006) }\end{array}$ \\
\hline FRIEND & UNESCO & $\begin{array}{l}\text { Hydrology (international) } \\
\text { (van Lanen et al., 2002; } \\
\text { Bonell et al., 2006) }\end{array}$ \\
\hline
\end{tabular}

Integrating information about human-water feedbacks into these data sets is another challenge for the community. The challenge relates to the determination of the most valuable kinds of information to collate, obtaining data sets that may be privately held or confidentially compiled by government agencies, and by virtue of its nature. For instance, archiving historical or legal information, or extracting quantitative metrics from such information to make it easy for hydrologists to use, this information is not a routine activity (Haberl et al., 2006; Redman et al., 2004). Booming opportunities in novel data collection techniques, including the use of human sensors, distributed sensors linked in to mobile phone or wireless networks; and the need to manage uncertainty in these data sets pose further challenges. Strong multi-disciplinary and multi-investigator partnerships could be valuable as ways to learn about techniques for gathering, storing, using and synthesizing these non-traditional data sets.

\subsubsection{Models and modeling frameworks}

Given the diversity of approaches that we have identified as being important for co-evolutionary modeling, there is a role for community-based model formulation projects and targeted model intercomparison exercises. Taking real problems as targets for investigation, model building could proceed from interdisciplinary discussions that clarify research questions, suitable state variables and critical feedbacks and couplings. Multiple different models could be crafted for the same system, each reflecting different philosophies and approaches. These models could form the basis for formal intercomparison exercises that attempt to illuminate the contribution of the different efforts. Such activities could be productively supported via existing synthesis centers such as SESYNC (http://www.sesync.org/) suitable for ecohydrological and socio-hydrologically focused modeling efforts; or NCED (http://www.nced.umn. $\mathrm{edu} /$ ) - for hydrological - land surface process studies, and can build off existing model intercomparison (e.g., http://www.eu-watch.org/watermip; Haddeland et al., 2011) and community modeling (e.g., http://www.cuahsi.org/ CommunityHydrologicModelingInitiatives.aspx) efforts.

\section{Conclusions}

We have argued that the long legacy of water resource management decisions places an imperative upon hydrologists to predict the behavior of water systems over a one hundredyear timescale that represents the potential lifetime of policy and infrastructure. Since this lifetime spans a period in which we anticipate rapid changes in many environmental subsystems, hydrologists are challenged to find ways to address the implications of these changes for water system behavior. It is unclear that the current reductionist, mechanistic framework for hydrology is well positioned to address this challenge (Killeen and Abrajano, 2008; Torgersen, 2006; Wagener et al., 2010). Specific issues that confront hydrologists include identifying, describing and parameterizing the feedbacks between water and other systems; addressing uncertainty arising from changing systems on multiple timescales and developing methods to address the large and growing role of humans in water systems. Research that aims to address the goal of developing long-term predictive insight must contribute to the development, evaluation and improvement of co-evolutionary modeling approaches: we have suggested that theoretical efforts in this area will be supported by empirical studies along long timescales (hydrologic reconstruction), over gradients in environmental (including human) features at the catchment scale (comparative hydrology), and by new developments in the strategic use of data to constrain, improve and evaluate models (model-data learning). While there are precedents for all these research activities, we suggest focusing research efforts on these approaches 
with a particular emphasis on understanding system change. Community-led "big-science" initiatives could play a significant role in these efforts, whether focused on data curation, observational networks or interdisciplinary model development. Yet none of these scientific approaches lie beyond the scope of individual researchers worldwide, and it seems highly probable that any big science initiatives in this arena would generate positive "trickle-down" impacts for individual researchers generally (Torgersen, 2006).

Although we have focused here on new research avenues to support hydrological modeling, there remain important outstanding needs to address the practice and implementation of water science and water resources management more broadly. Engagement and acknowledgement of the legitimacy of community-based knowledge, development of broad coalitions of action that span research, political, and grassroots dimensions, and growing awareness of the importance of local context for successful resource management still need to be built into decision-making and water resource management processes. These issues will arise fundamentally in the research and implementation of the new discipline of sociohydrology, and are likely to be exceedingly important for solving water problems. Hydrologists will also be faced with the challenges of learning how to implement these modes of practice (Lane, 2013).

Although we have focused on the major challenges that inhibit our ability to make predictions that support management decisions, this research agenda does not advocate abandoning fundamental hydrologic research. We do, however, argue that the pragmatic focus adopted here can improve the likelihood that this fundamental science can contribute to solving societally relevant problems - the core aim of use-inspired science. The use-inspired approach is strongly supported by the launch of Panta Rhei, the new international decadal initiative of the International Association of Hydrological Sciences (IAHS) (Montanari et al., 2013), which focuses on changing human and water systems; and by the synergies already identified between the research program outlined in this paper and that of CUAHSI (2010). Such synergies can provide the building blocks for an international hydrological effort to address the effects of hydrological change on society in our ever more human dominated world. These efforts will provide more opportunities for hydrological researchers to synthesize across places, disciplines and timescales, to explore non-stationary complex systems, and to engage with the wide, deep footprint of human intervention on water systems worldwide.

Acknowledgements. The work on this paper has been in part supported by a supplementary grant from the US National Science Foundation to the Hydrologic Synthesis project "Water Cycle Dynamics in a Changing Environment: Advancing Hydrologic Science through Synthesis" (NSF grant EAR-0636043, PIs: M. Sivapalan, P. Kumar, B. L. Rhoads, and D. Wuebbles). Special thanks to Jun Abrajano of the NSF for initiating the supplementary project and to NSF program managers Doug James and Tom Torgersen for their encouragement. This paper is a major outcome of several years of grassroots activities that involved over $40 \mathrm{sci}-$ entists, and which culminated in a white paper called "Predictions under Change (PUC): Water, Earth and Biota in the Anthropocene" (M. Sivapalan, Editor). We are grateful to all the participants (listed in the PUC Report) for their valuable inputs, in various capacities, to this synthesis activity. The work was (partially) developed within the framework of the Panta Rhei Research Initiative of the International Association of Hydrological Sciences (IAHS). The authors thank Hal Voepel, Dingbao Wang, Mary Yaeger, and Sheng Ye for their assistance with figure preparation, and Ashwini Chhatre for helpful comments. S. E. Thompson acknowledges funding support from NSF grant EAR-1013339. G. Blöschl acknowledges funding support from ERC Advanced Grant 291152 FloodChange.

Edited by: D. Gerten

\section{References}

Abrahams, A. D. and Ponczynski, J. J.: Drainage density in relation to precipitation intensity in the USA, J. Hydrol., 75, 383-388, 1984.

Abrahart, R. J., Anctil, F., Coulibaly, P., Dawson, C. W., Mount, N. J., See, L., Shamseldin, A. Y., Solomatine, D., Toth, E., and Wilby, R. L.: Two decades of anarchy? Emerging themes and outstanding challenges for neural network river forecasting, Prog. Phys. Geogr., 36, 480-513, 2012.

Anderson, J., Hoar, T., Raeder, K., Liu, H., Collins, N., Torn, R., and Avellano, A.: The Data Assimilation Research Testbed: A community facility, B. Am. Meteorol. Soc., 90, 1283-1296, 2009.

An Heyvaert, V. M. and Baeteman, C.: A Middle to Late Holocene avulsion history of the Euphrates river: a case study from Tell edDìr, Iraq, Lower Mesopotamia, Quaternary Sci. Rev., 27, 24012410, 2008.

Baker, V. R., Benito, G., and Rudoy, A. N.: Paleohydrology of late Pleistocene superflooding, Altay mountains, Siberia, Science, 259, 348-350, 1993.

Baldocchi, D., Falge, E., Gu, L., Olson, R., Hollinger, D., Running, S., Anthoni, P., Bernhofer, C., Davis, K., and Evans, R.: FLUXNET: a new tool to study the temporal and spatial variability of ecosystem-scale carbon dioxide, water vapor, and energy flux densities, B. Am. Meteorol. Soc., 82, 415-2434, 2001.

Beck, M. B.: Grand challenges for environmental modeling, Environmental Modelling and Software, 25, 611-612, 2010.

Bekele, E. G. and Nicklow, J. W.: Multiobjective management of ecosystem services by integrative watershed modeling and evolutionary algorithms, Water Resour. Res., 41, W10406, doi:10.1029/2005WR004090, 2005.

Bell, J. L., Sloan, L. C., Revenaugh, J., and Duffy, P. B.: Evaluation of Northern Hemisphere natural climate variability in multiple temperature reconstructions and global climate model simulations, Global Planet. Change, 37, 19-32, doi:10.1016/S09218181(02)00189-3, 2003.

Beven, K.: Prophecy, reality and uncertainty in distributed hydrological modeling, Adv. Water Resour., 16, 41-51, 1993.

Beven, K. J.: Uniqueness of place and process representations in hydrological modelling, Hydrol. Earth Syst. Sci., 4, 203-213, doi:10.5194/hess-4-203-2000, 2000. 
Beven, K.: Searching for the Holy Grail of scientific hydrology: $Q_{t}=(S, R, \Delta t) A$ as closure, Hydrol. Earth Syst. Sci., 10, 609618, doi:10.5194/hess-10-609-2006, 2006a.

Beven, K.: A manifesto for the equifinality thesis, J. Hydrol., 320, 18-36, 2006b.

Blöschl, G.: Hydrologic synthesis: Across processes, places, and scales, Water Resour. Res., 42, W03S02, doi:10.1029/2005WR004319, 2006.

Blöschl, G. and Montanari, A.: Climate change impacts - throwing the dice?, Hydrol. Process., 24, 374-381, 2010.

Blöschl, G., Sivapalan, M., Wagener, T., Viglione, A., and Savenije, H. H. G.: Runoff prediction in ungauged basins: Synthesis across processes, places and scales, Cambridge University Press, Cambridge, 2013.

Bonell, M., McDonnell, J. J., Scatena, F., Seibert, J., Uhlenbrook, S., and Van Lanen, H. A.: HELPing FRIENDs in PUBs: charting a course for synergies within international water research programmes in gauged and ungauged basins, Hydrol. Process., 20, 1867-1874, 2006.

Borner, K., Dall'Asta, L., Ke, W. M., and Vespigiani, A.: Studying the emerging global brain: Analyzing and visualizing the impact of co-authorship teams, Complexity, 10, 57-67, doi:10.1002/cplx.20078, 2005.

Borowski, I., Le Bourhis, J.-P., Pahl-Wostl, C., and Barraqué, B.: Spatial misfit in participatory river basin management: effects on social learning. a comparative analysis of German and French case studies, Ecol. Soc., 13, 7, 2008.

Braden, J., Brown, D., Dozier, J., Gober, P., Hughes, S., Maidment, D., Schneider, S., Schultz, P., Shortle, J., Swallow, S., and Werner, C.: Social science in a water observing system, Water Resour. Res., 45, W11301, doi:10.1029/2009WR008216, 2009.

Bradley, C., Baker, A., Jex, C. N., and Leng, M. J.: Hydrological uncertainties in the modelling of cave drip-water ${ }^{18} \mathrm{O}$ and the implications for Stalagmite palaeoclimate reconstructions, Quaternary Sci. Rev., 29, 2201-2214, 2010.

Brantley, S. L., White, T. S., White, A. F., Sparks, D., Richter, D., Pregitzer, K., Derry, L., Chorover, J., Chadwick, O., April, R., Anderson, S., and Amundson, R.: Frontiers in exploration of the Critical Zone Report of a workshop sponsored by the National Science Foundation (NSF), Newark, Delaware, p. 30, 2006.

Brazdil, R. and Kundzewicz, Z. W.: Historical hydrology, Hydrolog. Sci. J., 51, 733-738, doi:10.1623/hysj.51.5.733, 2006.

Brazdil, R., Kundzewicz, Z. W., and Benito, G.: Historical hydrology for studying flood risk in Europe, Hydrolog. Sci. J., 51, 739764, doi:10.1623/hysj.51.5.739, 2006.

Brázdil, R., Chromá, K., Valášek, H., and Dolák, L.: Hydrometeorological extremes derived from taxation records for south-eastern Moravia, Czech Republic, 1751-1900 AD, Clim. Past, 8, 467481, doi:10.5194/cp-8-467-2012, 2012.

Brooks, P. D., Troch, P. A., Durcik, M., Gallo, E., and Schlegel, M.: Quantifying regional scale ecosystem response to changes in precipitation: Not all rain is created equal, Water Resour. Res., 47, W00J08, doi:10.1029/2010WR009762, 2011.

Brown, A.: An integrated 1500 year record for the river Trent (UK) using geomorphological and geoarchaeological data, EGU General Assembly Conference Abstracts, Vienna, 13772, 2009.

Brown, C. and Lall, U.: Water and economic development: The role of variability and a framework for resilience, Natural Resources
Forum, 30, 306-317, doi:10.1111/j.1477-8947.2006.00118.x, 2006.

Budyko, M. I. and Miller, D. H.: Climate and life, Vol. 508, Academic Press, New York, 1974.

Burton, C. and Cutter, S.: Levee failures and social vulnerability in the Sacramento-San Joaquin Delta area, California, Nat. Hazards Rev., 9, 136-149, doi:10.1061/(ASCE)15276988(2008)9:3(136), 2008.

Carpenter, S. R., Stanley, E. H., and Vander Zanden, M. J.: State of the world's freshwater ecosystems: Physical, chemical, and biological changes, Annu. Rev. Environ. Resour., 36, 75-99 2011.

Carrillo, G., Troch, P. A., Sivapalan, M., Wagener, T., Harman, C., and Sawicz, K.: Catchment classification: hydrological analysis of catchment behavior through process-based modeling along a climate gradient, Hydrol. Earth Syst. Sci., 15, 3411-3430, doi:10.5194/hess-15-3411-2011, 2011.

Characklis, G., Kirsch, B., Ramsey, J., Dillard, K., and Kelley, C. T.: Developing portfolios of water supply transfers, Water Resour. Res., 42, W05403, doi:10.1029/2005WR004424, 2006.

Clarke, C. J., George, R. J., Bell, R. W., and Hatton, T. J.: Dryland salinity in south-western Australia: its origins, remedies, and future research directions, Aust. J. Soil Res., 40, 93-113, 2002.

Clarke, R. T.: Hydrological prediction in a non-stationary world, Hydrol. Earth Syst. Sci., 11, 408-414, doi:10.5194/hess-11-4082007, 2007.

Cohn, T. A. and Lins, H. F.: Nature's Style: Naturally Trendy, Geophys. Res. Lett., 32, L23402, doi:10.1029/2005GL024476, 2005.

Congress of the United States: US Endangered Species Preservation Act, in: P.L. 89-669, 80 Stat. 926, Washington, D.C., USA, 1966.

Coulibaly, P., Anctil, F., and Bobee, B.: Multivariate reservoir inflow forecasting using temporal neural networks, J. Hydrol. Eng., 6, 367-376, 2001.

Crutzen, P. J. and Stoemer, E. F.: The Anthropocene, Global Change Newslett., 41, 17-18, 2000.

CUAHSI: Water in a dynamic planet - a five year strategic plan for water science, Consortium of Universities for the Advancement of Water Science, Inc., Washington, D.C., USA, 2010.

Dakos, V., Scheffer, M., Van Nes, E. H., Brovkin, V., Petoukhov, V., and Held, H.: Slowing down as an early warning signal for abrupt climate change, P. Natl. Acad. Sci., 105, 14308-14312, 2008.

Daniels, S. E. and Walker, G. B.: Working through environmental conflict: The collaborative learning approach, Praeger Publishers, Westport CT, 2001.

Davis, D. R., Duckstein, L., and Krzysztofowicz, R.: Worth of hydrologic data for nonoptimal decision-making, Water Resour. Res., 15, 1733-1742, 1979.

DeAngelis, A., Dominguez, F., Fan, Y., Robock, A., Kustu, M. D., and Robinson, D.: Evidence of enhanced precipitation due to irrigation over the Great Plains of the United States, J. Geophys. Res., 115, D15115, doi:10.1029/2010JD013892, 2010.

Dent, C. L., Cumming, G. S., and Carpenter, S. R.: Multiple states in river and lake ecosystems, Philos. T. Roy. Soc. B, 357, 635645, 2002.

Dessai, S., Hulme, M., Lempert, R., and Pielke Jr., R.: Climate prediction: a limit to adaptation?, in: Adapting to Climate Change: Thresholds, Values, Governance, edited by: Adger, W. N., Lorenzoni, I., and O’Brien, K., Cambridge University Press, Cambridge, 64-78, 2009. 
Detto, M., Molini, A., Katul, G., Stoy, P., Palmroth, S., and Baldocchi, D.: Causality and persistence in ecological systems: a nonparametric spectral Granger causality approach, Am. Naturalist, $179,524-535,2012$.

Di Baldassarre, G., Castellarin, A., and Brath, A.: Analysis of the effects of levee heightening on flood propagation: example of the River Po, Italy, Hydrolog. Sci. J., 54, 1007-1017, 2009.

Di Baldassarre, G., Kooy, M., Kemerink, J. S., and Brandimarte, L.: Towards understanding the dynamic behaviour of floodplains as human-water systems, Hydrol. Earth Syst. Sci., 17, 3235-3244, doi:10.5194/hess-17-3235-2013, 2013.

D'Odorico, P., Laio, F., and Ridolfi, L.: A probabilistic analysis of fire-induced tree-grass coexistence in savannas, Am. Naturalist, 167, E79-E87, 2006.

D'Odorico, P., Laio, F., and Ridolfi, L.: Does globalization of water reduce societal resilience to drought?, Geophysical Research Letters, 37, L13403, 2010.

Dominguez, F., Rivera, E., Lettenmaier, D., and Castro, C.: Changes in winter precipitation extremes for the western United States under a warmer climate as simulated by regional climate models, Geophys. Res. Lett., 39, L05803, doi:10.1029/2011GL050762, 2012.

Donohue, R. J., Roderick, M. L., McVicar, T. R., and Farquhar, G. D.: Impact of $\mathrm{CO}_{2}$ fertilization on maximum foliage cover across the globe's warm, arid environments, Geophys. Res. Lett., 40, 3031-3035, doi:10.1002/grl.50563, 2013.

Dooge, J. C. I.: Looking for hydrologic laws, Water Resour. Res., 22, 46s-58s, 1986

Dooge, J. C. I.: Hydrology in perspective, Hydrolog. Sci. J., 33, 6185, 1988.

Drécourt, J., Madsen, H., and Rosbjery, D.: Bias aware Kalman filters: Comparison and improvements, Adv. Water Resour., 29, 707-718, 2006.

Duan, Q., Schaake, J., Andreassian, V., Franks, S., Goteti, G., Gupta, H., Gusev, Y., Habets, F., Hall, A., and Hay, L.: Model Parameter Estimation Experiment (MOPEX): An overview of science strategy and major results from the second and third workshops, J. Hydrol., 320, 3-17, 2006.

Dunne, T., Freyburg, D. L., McKnight, D. M., Wood, E. F., Phillips, F. M., and Burges, S. J.: Hydrologic sciences. Taking stock and looking ahead, edited by: Commission on Geosciences, E. a. R., National Research Council, National Academy of Sciences, Washington, D.C., USA, 1998.

Earl, D. J. and Deem, M. W.: Evolvability is a selectable trait, P. Natl. Acad. Sci., 101, 11531-11536, 2004.

Edwards, P. N.: History of climate modeling, Wiley Interdisciplinary Reviews, Climate Change, 2, 128-139, 2011.

Einsele, G. and Hinderer, M.: Terrestrial sediment yield and the lifetimes of reservoirs, lakes, and larger basins, Geol. Rundsch., 86, 288-310, doi:10.1007/s005310050141, 1997.

Endreny, T. A. and Diemont, S.: Methods for assessing stormwater management at archaeological sites: Copan Ruins case study, J. Archaeol. Sci., 39, 2637-2642, doi:10.1016/j.jas.2012.04.022, 2012.

Fahey, B., and Jackson, R.: Hydrological impacts of converting native forests and grasslands to pine plantations, South Island, New Zealand, Agr. Forest Meteorol., 84, 69-82, doi:10.1016/S01681923(96)02376-3, 1997
Falkenmark, M. and Chapman, T. G.: Comparative hydrology: An ecological approach to land and water resources, UNESCO, 479 pp., 1989.

Falkenmark, M. and Lannerstad, M.: Consumptive water use to feed humanity - curing a blind spot, Hydrol. Earth Syst. Sci., 9, 1528, doi:10.5194/hess-9-15-2005, 2005.

Feldman, D. L.: Preventing the repetition: Or, what Los Angeles' experience in water management can teach Atlanta about urban water disputes, Water Resou. Res., 45, W04422, doi:10.1029/2008WR007605, 2009.

Flores, A. N., Ivanov, V. Y., Entekhabi, D., and Bras, R. L.: Impact of hillslope-scale organization of topography, soil moisture, soil temperature, and vegetation on modeling surface microwave radiation emission, IEEE T. Geosci. Remote, 47, 2557-2571, 2009.

Foley, J. A., Levis, S., Costa, M. H., Cramer, W., and Pollard, D.: Incorporating dynamic vegetation cover within global climate models, Ecol. Appl., 10, 1620-1632, doi:10.2307/2641227, 2000.

Foley, J. A., Costa, M. H., Delire, C., Ramankutty, N., and Snyder, P.: Green surprise? How terrestrial ecosystems could affect earth's climate, Front. Ecol. Environ., 1, 38-44, doi:10.2307/3867963, 2003.

French, K. D., Duffy, C. J., and Bhatt, G.: The hydroarchaeological method: A case study at the Maya site of Palenque, Latin Am. Antiquity, 23, 29-50, 2012.

Ganopolski, A., Rahmstorf, S., Petoukhov, V., and Claussen, M.: Simulation of modern and glacial climates with a coupled global model of intermediate complexity, Nature, 391, 351-356, 1998.

Garner, E. L. and Ouellette, M.: Future Shock-The Law of the Colorado River in the Twenty-First Century, Ariz. St. LJ, 27, 469506, 1995.

Gerten, D.: A vital link: water and vegetation in the Anthropocene, Hydrol. Earth Syst. Sci., 17, 3841-3852, doi:10.5194/hess-173841-2013, 2013.

Gleick, P. H. and Palaniappan, M.: Peak water limits to freshwater withdrawal and use, P. Natl. Acad. Sci., 107, 11155-11162, doi:10.1073/pnas.1004812107, 2010.

Goldenfeld, N., and Woese, C.: Life is physics: Evolution as a collective phenomenon far from equilibrium, Annu. Rev. Condens. Mat. Phys., 2, 375-399, 2011.

Goodall, J. L., Horsburgh, J. S., Whiteaker, T. L., Maidment, D. R., and Zaslavsky, I.: A first approach to web services for the National Water Information System, Environ. Model. Softw., 23, 404-411, 2008.

Gual, M. A. and Norgaard, R. B.: Bridging ecological and social systems coevolution: A review and proposal, Ecol. Econom., 69, 707-717, doi:10.1016/j.ecolecon.2008.07.020, 2010.

Guardiola-Claramonte, M., Troch, P. A., Breshears, D. D., Huxman, T. E., Switanek, M. B., Durcik, M., and Cobb, N. S.: Decreased streamflow in semi-arid basins following drought-induced tree die-off: A counter-intuitive and indirect climate impact on hydrology, J. Hydrol., 406, 225-233, doi:10.1016/j.jhydrol.2011.06.017, 2011.

Gupta, H., Wagener, T., and Liu, Y.: Reconciling theory with observations: elements of a diagnostic approach to model evaluation, Hydrol. Process., 22, 3802-3813, 2008.

Gupta, V., Duffy, C. J., Grossman, R., Krajewski, W., Lall, U., McCaffrey, M., Milne, B., Pielke, R., Reckhow, K., and Swanson, F: A Framework for reassessment of basic 
research and educational priorities in hydrologic sciences Report of a Hydrology Workshop, Albuquerque, NM, 31 January1 February 1999, to the NSF-GEO Directorate, Albuquerque, NM, http://cires.colorado.edu/collaboration/projects/hydrology/ history/40.html (last access: December 2013), 2000.

Haberl, H., Winiwarter, V., Andersson, K., Ayres, R. U., Boone, C., Castillo, A., Cunfer, G., Fischer-Kowalski, M., Freudenburg, W. R., and Furman, E.: From LTER to LTSER: Conceptualizing the socioeconomic dimension of long-term socioecological research, Ecol. Soc., 11, 13, 2006.

Haddeland, I., Clark, D. B., Franssen, W., Ludwig, F., Voß, F., Arnell, N. W., Bertrand, N., Best, M., Folwell, S., Gerten, D., Gomes, S., Gosling, S. N., Hagemann, S., Hanasaki, N., Harding, R., Heinke, J., Kabat, P., Koirala, S., Oki, T., Polcher, J., Stacke, T., Viterbo, P., Weedon, G. P., and Yeh, P.: Multimodel Estimate of the Global Terrestrial Water Balance: Setup and First Results, J. Hydrometeorol., 12, 869-884, doi:10.1175/2011jhm1324.1, 2011.

Haimes, Y.: The worth of streamflow data in water resources planning: Computational results, Water Resour. Res., 15, 1335-1342, 1979.

Hall, D. L., Graham, J., More, L., and Rimland, J. C.: Test and evaluation of soft/hard information fusion systems: A test environment, methodology and initial data sets, 13th Conference on Information Fusion (FUSION), Edinburgh, 1-7, 2010.

Hall, K. L., Feng, A. X., Moser, R. P., Stokols, D., and Taylor, B. K.: Moving the science of team science forward - Collaboration and creativity, Am. J. Prevent. Med., 35, S243-S249, doi:10.1016/j.amepre.2008.05.007, 2008.

Hanson, P. C.: A grassroots approach to sensor and science networks, Front. Ecol. Environ., 5, p. 343, 2007.

Hargreaves, J. C., Paul, A., Ohgaito, R., Abe-Ouchi, A., and Annan, J. D.: Are paleoclimate model ensembles consistent with the MARGO data synthesis?, Clim. Past, 7, 917-933, doi:10.5194/cp-7-917-2011, 2011.

Harou, J., Pulido-Velazquez, M., Rosenberg, D., Medellin-Azuara, J., Lund, J., and Howitt, R.: Hydro-economic models: Concepts, design, applications, and future propects, J. Hydrol., 375, 627643, 2009.

Hatala, J. A., Detto, M., and Baldocchi, D. D.: Gross ecosystem photosynthesis causes a diurnal pattern in methane emission from rice, Geophysical Research Letters, 39, 2012.

Hipsey, M. R. and Arheimer, B.: Challenges for water-quality research in the new IAHS decade, in: Proceedings of H04, Hydrology Under Societal and Environmental Change - Understanding Freshwater Quality Problems in a Changing World, Gothenburg, Sweden, 2013,

Hooper, R., Maidment, D., Helly, J., Kumar, P., and Piasecki, M.: CUAHSI Hydrologic Information Systems, Proceedings of the 20th International Conference on Interactive Information and Processing Systems (IIPS) for Meteorology, Oceanography and Hydrology, American Meteorological Society, Seattle, WA, 2004 ,

Hrachowitz, M., Savenije, H. H. G., Blöschl, G., McDonnell, J. J., Sivapalan, M., Pomeroy, J. W., Arheimer, B., Blume, T., Clark, M. P., Ehret, U., Fenicia, F., Freer, J. E., Gelfan, A., Gupta, H. V., Hughes, D., Hut, R. W., Montanari, A., Pande, S., Tetzlaff, D., Troch, P. A., Uhlenbrook, S., Wagener, T., Winsemius, H. C., Woods, R. A., Zehe, E., and Cudennec, C.: A decade of
Predictions in Ungauged Basins (PUB) - a review, Hydrolog. Sci. J., 58, 1-58, doi:10.1080/02626667.2013.803183, 2013.

Huang, Y., Leroy, S., and Goody, R. M.: Discriminating between climate observations in terms of their ability to improve an ensemble of climate predictions, P. Natl. Acad. Sci., 108, 1040510409, doi:10.1073/pnas.1107403108, 2011.

Hundley, N.: Water and the West: the Colorado River Compact and the politics of water in the American West, Univ. of California Press, Berkeley, California, 2009.

Huntingford, C., Jones, R., Prudhomme, C., Lamb, R., Gash, J. H., and Jones, D. A.: Regional climate-model predictions of extreme rainfall for a changing climate, Q. J. Roy. Meteorol. Soc., 129, 1607-1621, 2006.

Huntjens, P., Pahl-Wostl, C., Rihoux, B., Schläter, M., Flachner, Z., Neto, S., Koskova, R., Dickens, C., and Nabide Kiti, I.: Adaptive water management and policy learning in a changing climate: a formal comparative analysis of eight water management regimes in Europe, Africa and Asia, Environ. Policy Govern., 21, 145163, 2011.

Irwin, R. S., Flaherty, H. M., French, C. T., Cody, S., Chandler, M. W., Connolly, A., Lilly, C. M., and Operations, U. M. M. C. C.: Interdisciplinary Collaboration The Slogan That Must Be Achieved for Models of Delivering Critical Care to Be Successful, Chest, 142, 1611-1619, doi:10.1378/chest.12-1844, 2012.

Jackson, R. B., Carpenter, S. R., Dahm, C. N., McKnight, D. M., Naiman, R. J., Postel, S. L., and Running, S. W.: Water in a changing world, Ecol. Appl., 11, 1027-1045, 2001.

Jarrett, R. D.: Paleohydrology and its value in analyzing floods and droughts, US Geological Survey Water-Supplementary Paper 2375, US Geological Survey, Reston, Virginia, 105-116, 1991.

Jencso, K. G., McGlynn, B. L., Gooseff, M. N., Wondzell, S. M., Bencala, K. E., and Marshall, L. A.: Hydrologic connectivity between landscapes and streams: Transferring reach- and plot-scale understanding to the catchment scale, Water Resour. Res., 45, W04428, doi:10.1029/2008WR007225, 2009.

Jencso, K. G., McGlynn, B. L., Gooseff, M. N., Bencala, K. E., and Wondzell, S. M.: Hillslope hydrologic connectivity controls riparian groundwater turnover: Implications of catchment structure for riparian buffering and stream water sources, Water Resour. Res., 46, W10524, doi:10.1029/2009WR008818, 2010.

Jewitt, G.: Can integrated water resources management sustain the provision of ecosystem goods and services?, Phys. Chem. Earth A/B/C, 27, 887-895, 2002.

Kandasamy, J., Sounthararajah, D., Sivabalan, P., Chanan, A., Vigneswaran, S., and Sivapalan, M.: Socio-hydrologic drivers of the Pendulum Swing between agriculture development and environmental health: a case study from Murrumbidgee River Basin, Australia, Hydrol. Earth Syst. Sci. Discuss., 10, 7197-7233, doi:10.5194/hessd-10-7197-2013, 2013.

Kasprzyk, J. R., Nataraj, S., Reed, P. M., and Lempert, R. J.: ManyObjective Robust Decision Making for Complex Environmental Systems Undergoing Change, Environ. Model. Softw., 42, 5571, 2013.

Kates, R. W., Colten, C. E., Laska, S., and Leatherman, S. P.: Reconstruction of New Orleans after Hurricane Katrina: a research perspective, P. Natl. Acad. Sci., 103, 14653-14660, 2006. 
Kaushal, S., Pace, M., Groffman, P., Band, L., Belt, K., Mayer, P., and Welty, C.: Land use and climate variability amplify contaminant pulses, EOS, 91, 221-228, 2010.

Kefi, S., Rietkerk, M., Alados, C. L., Pueyo, Y., Papanastasis, V. P., ElAich, A., and de Ruiter, P. C.: Spatial vegetation patterns and imminent desertification in Mediterranean arid ecosystems, Nature, 449, 213-215, doi:10.1038/nature06111, 2007.

Killeen, T. L. and Abrajano, T. J.: Understanding the triple point, Elements, Mineralogical Society of America,, p. 298, 2008.

King, C. and Webber, M.: The water intensity of the plugged-in automotive economy, Environ. Sci. Technol., 42, 4305-4311, 2008.

Klemes, V.: The Hurst phenomenon - A puzzle?, Water Resour. Res., 10, 675-688, doi:10.1029/WR010i004p00675, 1974.

Kollat, J. B. and Reed, P.: Addressing bias and uncertainty in groundwater transport forecasts for a three-dimensional physical aquifer experiment, Geophys. Res. Lett., 35, L17402, doi:10.1029/2008GL035021, 2008.

Kollat, J. B., Reed, P. M., and Maxwell, R.: Many-objective Groundwater Monitoring Network Design using Bias-Aware Ensemble Kalman Filtering, Evolutionary Optimization, and Visual Analytics, Water Resour. Res., 47, W02529, doi:10.1029/2010WR009194, 2011.

Koutsoyiannis, D.: Non-stationarity versus scaling in hydrology, J. Hydrol., 324, 239-254, doi:10.1016/j.jhydrol.2005.09.22, 2006.

Koutsoyiannis, D.: HESS Opinions "A random walk on water", Hydrol. Earth Syst. Sci., 14, 585-601, doi:10.5194/hess-14-5852010, 2010.

Koutsoyiannis, D., Makropoulos, C., Langousis, A., Baki, S., Efstratiadis, A., Christofides, A., Karavokiros, G., and Mamassis, N.: HESS Opinions: "Climate, hydrology, energy, water: recognizing uncertainty and seeking sustainability", Hydrol. Earth Syst. Sci., 13, 247-257, doi:10.5194/hess-13-247-2009, 2009.

Kratz, T. K., Deegan, L. A., Harmon, M. E., and Lauenroth, W. K.: Ecological variability in space and time: Insights gained from the US LTER program, Bioscience, 53, 57-67, 2003.

Kumar, P.: Typology of hydrologic predictability, Water Resour. Res., 47, W00H05, doi:10.1029/2010WR009769, 2011.

Laio, F. and Tamea, S.: Verification tools for probabilistic forecasts of continuous hydrological variables, Hydrol. Earth Syst. Sci., 11, 1267-1277, doi:10.5194/hess-11-1267-2007, 2007.

Lal, M.: Climatic change - Implications for India's water resources, in: Climate Change and Water Resources in South Asia, edited by: Monirul Qader Mizra, M. and Ahmad, Q. K., Taylor and Francis, Leiden, the Netherlands, 155-196, 2005.

Lal, M.: Implications of climate change in sustained agricultural productivity in South Asia, Reg. Environ. Change, 11, 79-94, 2011.

Lane, S. N.: Acting, predicting and intervening in a sociohydrological world, Hydrol. Earth Syst. Sci. Discuss., 10, 1065910717, doi:10.5194/hessd-10-10659-2013, 2013.

Langbein, W. B.: Overview of conference on hydrologic data networks, Water Resour. Res., 15, 1867-1871, 1979.

Larson, E. L., Landers, T. F., and Begg, M. D.: Building Interdisciplinary Research Models: A Didactic Course to Prepare Interdisciplinary Scholars and Faculty, Cts - Clin. Translat. Sci., 4, 38-41, doi:10.1111/j.1752-8062.2010.00258.x, 2011.

Lean, J., Beer, J., and Bradley, R.: Reconstruction of solar irradiance since 1610: Implications for climate change, Geophys. Res. Lett., 22, 3195-3198, 1995.
Lempert, R.: A new decision sciences for complex systems, P. Natl. Acad. Sci., 99, 7309-7313, 2002.

Leung, L. R., Collins, B., and Famiglietti, J.: Community Modeling and Long-Term Predictions of the Integrated Water Cycle, Washington, D.C., USA, 2013.

Lin, H., Bouma, J., Wilding, L., Richardson, J., Kutilek, M., and Nielsen, D.: Advances in hydropedology, Adv. Agron., 85, 1-89, 2005.

Lindenmayer, D., and Likens, G.: Adaptive monitoring: a new paradigm for long-term research and monitoring, Trends Ecol. Evol., 24, 482-486, 2009.

Lins, H. F.: USGS Hydro-Climatic Data Network 2009, US Geological Survey Fact Sheet 2012-3047, US Geological Survey, Reston, Virginia, 1-4, 2012.

Lloyd, J. and Farquhar, G. D.: Effects of rising temperatures and $\left[\mathrm{CO}_{2}\right]$ on the physiology of tropical forest trees, Philos. T. Roy. Soc. B, 363, 1811-1817, doi:10.1098/rstb.2007.0032, 2008.

Loarie, S. R., Duffy, P. B., Hamilton, H., Asner, G. P., Field, C. B., and Ackerly, D. D.: The velocity of climate change, Nature, 462, 1052-1055, 2009.

Lowman, M., D’Avanzo, C., and Brewer, C.: A national ecological network for research and education, Science, 323, 1172-1173, 2009.

Lowry, D. and Morrill, C.: Changes in the global hydrological cycle: Lessons from modeling lake levels at the last glacial maximum, AGU Fall Meeting Abstracts, Wahington, D.C., USA, 2011.

Luo, P., Takara, K., He, B., and Nover, D.: Paleo-flood simulation of the Kamo River Basin using a grid-cell distributed rainfallrunoff model, J. Flood Risk Manage., doi:10.1111/jfr3.12038, in press, 2013.

Mann, M. E. and Rutherford, S.: Climate reconstruction using pseudoproxies, Geophys. Res. Lett., 29, 1501, doi:10.1029/2001GL014554, 2002.

Margolis, E. Q., Meko, D. M., and Touchan, R.: A tree-ring reconstruction of streamflow in the Santa Fe River, New Mexico, J. Hydrol., 397, 118-127, 2011.

Markonis, Y. and Koutsoyiannis, D.: Climatic variability over time scales spanning nine orders of magnitude: Connecting Milankovitch cycles with Hurst-Kolmogorov dynamics, Surv. Geophys., 34, 181-207, 2013.

Maurer, E., Stewart, I., Bonfils, C., Duffy, P., and Cayan, D.: Detection, attribution, and sensitivity of trends toward earlier streamflow in the Sierra Nevada, J. Geophys. Res., 112, D11118, doi:10.1029/2006JD008088, 2007.

McCormick, M.: History's changing climate: Climate science, genomics, and the emerging consilient approach to interdisciplinary history, J. Interdisc. Hist., 42, 251-273, 2011.

McDonnell, J. J., Sivapalan, M., Vache, K., Dunn, S., Grant, G., Haggerty, R., Hinz, C., Hooper, R., Kirchner, J., Roderick, M. L., Selker, J., and Weiler, M.: Moving beyond heterogeneity and process complexity: A new vision for watershed hydrology, Water Resour. Res., 43, W07301, doi:10.1029/2006wr005467, 2007.

McGuire, D. B.: Building and maintaining an interdisciplinary research team, Alzheimer Disease Assoc. Disord., 13, S17-S21, doi:10.1097/00002093-199904001-00006, 1999.

McLaughlin, D.: An integrated approach to hydrologic data assimilation: interpolation, smoothing, and filtering, Adv. Water Resour., 25, 1275-1286, 2002. 
McVicar, T. R., Roderick, M. L., Donohue, R. J., Li, L. T., Van Niel, T. G., Thomas, A., Grieser, J., Jhajharia, D., Himri, Y., Mahowald, N. M., Mescherskaya, A. V., Kruger, A. C., Rehman, S., and Dinpashoh, Y.: Global review and synthesis of trends in observed terrestrial near-surface wind speeds: Implications for evaporation, J. Hydrol., 416-417, 182-205, doi:10.1016/j.jhydrol.2011.10.024, 2012a.

McVicar, T. R., Roderick, M. L., Donohue, R. J., and Van Niel, T. G.: Less bluster ahead? Overlooked ecohydrological implications of global trends of terrestrial near-surface wind speeds, Ecohydrology, 54, 381-388, doi:10.1002/eco.1298, 2012b.

Merritts, D., Walter, R., Rahnis, M., Hartranft, J., Cox, S., Gellis, A., Potter, N., Hilgartner, W., Langland, M., and Manion, L.: Anthropocene streams and base-level controls from historic dams in the unglaciated mid-Atlantic region, USA, Philos. T. Roy. Soc. A, 369, 976-1009, 2011.

Metcalf, S. S., Wheeler, E., BenDor, T. K., Lubinski, K. S., and Hannon, B. M.: Sharing the floodplain: Mediated modeling for environmental management, Environ. Model. Softw., 25, 12821290, 2010.

Micklin, P. P.: Desiccation of the Aral Sea: a water management disaster in the Soviet Union, Science, 241, 1170-1176, 1988.

Milly, P. C. D., Wetherald, R. T., Dunne, K. A., and Delworth, T. L.: Increasing risk of great floods in a changing climate, Nature, 415, 514-517, 2002.

Milly, P. C. D., Betancourt, J., Falkenmark, M., Hirsch, R. M., Kundzewicz, Z., Lettenmaier, D. P., and Stouffer, R. J.: Stationarity is dead: Whither water management?, Science, 319, 573-574, doi:10.1126/science.1151915, 2008.

Mishra, A. and Coulibaly, P.: Developments in hydrometric network design: A review, Rev. Geophys., 47, RG2001, doi:10.1029/2007RG000243, 2009.

Moehring, C.: Robustness of statistical gossip and the Antarctic ozone hole, IMS Bull., 19, 540-545, 1990.

Molini, A., Katul, G. G., and Porporato, A.: Causality across rainfall time scales revealed by continuous wavelet transforms, J. Geophys. Res.,115, D14123, doi:10.1029/2009JD013016, 2010.

Montanari, A.: Uncertainty of hydrological predictions, in: Treatise on Water Science, edited by: Wilderer, P. A., Elsevier, Amsterdam, the Netherlands, 2011.

Montanari, A.: Hydrology of the Po River: looking for changing patterns in river discharge, Hydrol. Earth Syst. Sci., 16, 37393747, doi:10.5194/hess-16-3739-2012, 2012.

Montanari, A. and Koutsoyiannis, D.: A blueprint for process-based modeling of uncertain hydrological systems, Water Resour. Res., 48, W09555, doi:10.1029/2011WR011412, 2012.

Montanari, A., Shoemaker, C. A., and van de Giesen, N.: Introduction to special section on Uncertainty Assessment in Surface and Subsurface Hydrology: An overview of issues and challenges, Water Resour. Res., 45, W00B00, doi:10.1029/2009WR008471, 2009.

Montanari, A., Young, G., Savenije, H. H. G., Hughes, D., Wagener, T., Ren, L. L., Koutsoyiannis, D., Cudennec, C., Grimaldi, S., Blöschl, G., Sivapalan, M., Beven, K., Gupta, H., Arheimer, B., Huang, Y., Schumann, A., Post, D., Srinivasan, V., Boegh, E., Hubert, P., Harman, C. J., Thompson, S. E., Rogger, M., Hipsey, M., Toth, E., Viglione, A., Di Baldassarre, G., Schaefli, B., McMillan, H., Schymanski, S. J., Characklis, G., Yu, B., Pang, Z., and Belyaev, V.: Panta Rhei - everything flows: Change in hydrology and society - the IAHS Scientific Decade 2013-2022, Hydrolog. Sci. J., 58, 1256-1275, doi:10.1080/02626667.2013.809088, 2013.

Moore, R. W., Rajasekar, A., Conway, M., Schroeder, W., and Wan, M.: White Paper: National Data Infrastructure for Earth System Science, White Paper submitted to EarthCube project (http: //earthcube.ning.com/group/technology-resolutions (last access: 24 May 2013), 2011.

Morse, W. C., Nielsen-Pincus, M., Force, J. E., and Wulfhorst, J. D.: Bridges and barriers to developing and conducting interdisciplinary graduate-student team research, Ecol. Soc., 12, 8, 2007.

Moss, M. E.: Space, time, and the third dimension (model error), Water Resour. Res., 15, 1797-1800, 1979a.

Moss, M. E.: Some basic considerations in the design of hydrologic data networks, Water Resour. Res., 15, 1673-1676, 1979b.

Mundo, I. A., Masiokas, M. H., Villalba, R., Morales, M. S., Neukom, R., Le Quesne, C., Urrutia, R. B., and Lara, A.: Multicentury tree-ring based reconstruction of the Neuquén River streamflow, northern Patagonia, Argentina, Clim. Past, 8, 815829, doi:10.5194/cp-8-815-2012, 2012.

National Research Council: Informing Decisions in a Changing Climate, The National Academies Press, Washington, D.C., USA, 2009.

National Research Council: Challenges and Opportunities in the Hydrologic Sciences, Washington, D.C., USA, 2012.

Nepf, H. M.: Hydrodynamics of vegetated channels, J. Hydraul. Res., 50, 262-279, doi:10.1080/00221686.2012.696559, 2012.

Neuman, S. P.: Accounting for conceptual model uncertainty via maximum likelihood Bayesian model averaging, Acta Univ. Carolin.-Geolog., 46, 529-534, 2002.

Nicholson, S. E.: The methodology of historical climate reconstruction and its application to Africa, J. Afr. Hist., 20, 31-49, 1979.

Nunnery, J., Baker, P., Coe, M., and Fritz, S.: Reconstructing paleoprecipitation amounts using a terrestrial hydrologic model: Lake Titicaca and the Salar de Uyuni, Peru and Bolivia, AGU Fall Meeting Abstracts, San Francisco, USA, 2010.

O'Brien, K.: Global environmental change III: Closing the gap between knowledge and action, Prog. Human Geogr., 37, 587-596, doi:10.1177/0309132512469589, 2013.

Okin, G. S., D'Odorico, P., and Archer, S. R.: Impact of feedbacks on Chihuahuan desert grasslands: transience and metastability, J. Geophys. Res., 114, G01004, doi:10.1029/2008JG000833, 2009.

Olden, J. D., Kennard, M. J., and Pusey, B. J.: A framework for hydrologic classification with a review of methodologies and applications in ecohydrology, Ecohydrology, 5, 503-518, 2011.

Olmstead, S. M., Hanemann, W. M., and Stavins, R. N.: Water demand under alternative price structures, J. Environ. Econom. Manage., 54, 181-198, 2007.

Ostrom, E.: A general framework for analyzing sustainability of social-ecological systems, Science, 325, 419-422, 2009.

Pahl-Wostl, C., Craps, M., Dewulf, A., Mostert, E., Tabara, D., and Taillieu, T.: Social learning and water resources management, Ecol. Soc., 12, 5, 2007.

Pahl-Wostl, C., and Hare, M.: Processes of social learning in integrated resources management, J. Commun. Appl. Soc. Psychol., 14, 193-206, 2004.

Paola, C., Foufoula-Georgiou, E., Dietrich, W. E., Hondzo, M., Mohrig, D., Parker, G., Power, M. E., Rodriguez-Iturbe, I., Voller, V., and Wilcock, P.: Toward a unified science of the 
Earth's surface: Opportunities for synthesis among hydrology, geomorphology, geochemistry, and ecology, Water Resour. Res., 42, W03S10, doi:10.1029/2005WR004336, 2006.

Pelletier, J. D., Barron-Gafford, G. A., Breshears, D. D., Brooks, P. D., Chorover, J., Durcik, M., Harman, C. J., Huxman, T. E., Lohse, K. A., and Lybrand, R.: Coevolution of nonlinear trends in vegetation, soils, and topography with elevation and slope aspect: A case study in the Sky Islands of southern Arizona, J. Geophys. Res.-Earth, 118, 741-758, doi:10.1002/jgrf.20046, 2013

Poff, N., Richter, B., Arthington, A., Bunn, S., Naiman, R., Kendy, E., Acreman, M., Apse, C., Bledsoe, B., Freeman, M., Henriksen, J., Jacobson, R., Kennen, J., Merritt, D., O’Keeffe, J., Olden, J., Rogers, K., Tharme, R., and Warner, A.: The Ecological Limits of Hydrologic Alteration (ELOHA): a new framework for developing regional environmental flow standards Freshwater Biol., 55, 147-170, 2010.

Poff, N., Olden, J., and Strayer, D.: Climate change and freshwater fauna extinction risk, in: Saving a Million Species: Extinctions Risk from Climate Change, edited by: Hannah, L., Islang Press, Washington, D.C., 309-336, 2013.

Porter, J. E., Nagy, E., Kratz, T. K., Hanson, P., Collins, S. L., and Arzberger, P.: New eyes on the world: advanced sensors for ecology, Bioscience, 59, 385-397, 2009.

Postel, S. L. and Wolf, A. T.: Dehydrating conflict, Foreign Policy, 126, 60-67, 2001.

Qu, Y. and Duffy, C. J.: A semidiscrete finite volume formulation for multiprocess watershed simulation, Water Resour. Res., 43, W08419, doi:10.1029/2006WR005752, 2007.

Quian Quiroga, R., Kreuz, T., and Grassberger, P.: Event synchronization: a simple and fast method to measure synchronity and time delay patterns, Phys. Rev. E, 66, 041904, doi:10.1103/PhysRevE.66.041904, 2002.

Rasmussen, C.: Thermodynamic constraints on effective energy and mass transfer and catchment function, Hydrol. Earth Syst. Sci., 16, 725-739, doi:10.5194/hess-16-725-2012, 2012.

Rasmussen, C., Troch, P. A., Chorover, J., Brooks, P., Pelletier, J., and Huxman, T. E.: An open system framework for integrating critical zone structure and function, Biogeochemistry, 102, 1529, 2011.

Redman, C. L., Grove, J. M., and Kuby, L. H.: Integrating social science into the long-term ecological research (LTER) network: social dimensions of ecological change and ecological dimensions of social change, Ecosystems, 7, 161-171, 2004.

Reed, P. M. and Kasprzyk, J. R.: Water resources management: The myth, the wicked, and the future, J. Water Resour. Pl.-ASCE, 135, 411-413, 2009.

Reed, P. M. and Kollat, J. B.: Save Now, Pay Later? Multi-Period Many-Objective Groundwater Monitoring Design Given Systematic Model Errors and Uncertainty, Adv. Water Resour., 35, 55-68, 2012.

Reed, P. M., Brooks, R., Davis, K., DeWalle, D. R., Dressler, K. A., Duffy, C. J., Lin, H. S., Miller, D., Najjar, R., Salvage, K. M., Wagener, T., and Yarnal, B.: Bridging river basin scales and processes to assess human-climate impacts and the terrestrial hydrologic system, Water Resour. Res., 42, W07418, doi:10.1029/2005WR004153, 2006.

Refsgaard, J. C., van der Sluijs, J. P., Brown, J., and van der Keur, P.: A framework for dealing with uncertainty due to model structure error, Adv. Water Resour., 29, 1586-1597, doi:10.1016/j.advwatres.2005.11.013, 2006.

Rietkerk, M., Boerlijst, M. C., van Langevelde, F., HilleRisLambers, R., van de Koppel, J., Kumar, L., Prins, H. H., and de Roos, A. M.: Self-organization of vegetation in arid ecosystems, Am. Naturalist, 160, 524-530, 2002.

Röckstrom, J., Steffen, W., Noone, K., Persson, A., Chapin, F. S., Lambin, E., Lenton, T. M., Scheffer, M., Folke, C., Schellnhuber, H. J., Nykvist, B., de Wit, C. A., Hughes, T., van der Leeuw, S., Rodhe, H., Sorlin, S., Snyder, P. K., Costanza, R., Svedin, U., Falkenmark, M., Karlberg, L., Corell, R. W., Fabry, V. J., Hansen, J., Walker, B., Liverman, D., Richardson, K., Crutzen, P., and Foley, J.: Planetary boundaries: Exploring the safe operating space for humanity, Ecol. Soc., 14, 32, 2009.

Rodriguez-Iturbe, I.: Ecohydrology: A hydrologic perspective of climate, soil, and vegetation dynamies, Water Resour. Res., 36, 3-9, 2000.

Rose, A. B., Platt, K. H., and Frampton, C. M.: Vegetation change over 25 years in a New Zealand short-tussock grassland: Effects of sheep grazing and exotic invasions, New Zeal. J. Ecol., 19, 163-174, 1995.

Ruddell, B. L. and Kumar, P.: Ecohydrologic process networks: 1. Identification, Water Resour. Res., 45, W03419, doi:10.1029,2008ER007279, 2009a.

Ruddell, B. L. and Kumar, P.: Ecohydrologic process networks: 2. Analysis and characterization, Water Resour. Res., 45, W03420, doi:10.1029/2008WR007280, 2009b.

Salazar, M. R., Lant, T. K., Fiore, S. M., and Salas, E.: Facilitating Innovation in Diverse Science Teams Through Integrative Capacity, Small Group Res., 43, 527-558, doi:10.1177/1046496412453622, 2012.

Sawicz, K., Wagener, T., Sivapalan, M., Troch, P. A., and Carrillo, G.: Catchment classification: empirical analysis of hydrologic similarity based on catchment function in the eastern USA, Hydrol. Earth Syst. Sci., 15, 2895-2911, doi:10.5194/hess-15-28952011, 2011.

Scheffer, M., Carpenter, S., Foley, J. A., Folke, C., and Walker, B.: Catastrophic shifts in ecosystems, Nature, 413, 591-596, 2001.

Scheffer, M., Bascompte, J., Brock, W. A., Brovkin, V., Carpenter, S. R., Dakos, V., Held, H., Van Nes, E. H., Rietkerk, M., and Sugihara, G.: Early-warning signals for critical transitions, Nature, 461, 53-59, 2009.

Schimel, D., Hargrove, W., Hoffman, F., and MacMahon, J.: NEON: A hierarchically designed national ecological network, Front. Ecol. Environ., 5, p. 59, 2007.

Schroter, D., Cramer, W., Leemans, R., Prentice, I. C., Araujo, M. B., Arnell, N. W., Bondeau, A., Bugmann, H., Carter, T. R., Gracia, C. A., de la Vega-Leinert, A. C., Erhard, M., Ewert, F., Glendining, M., House, J. I., Kankaanpaa, S., Klein, R. J. T., Lavorel, S., Lindner, M., Metzger, M. J., Meyer, J., Mitchell, T. D., Reginster, I., Rounsevell, M., Sabate, S., Sitch, S., Smith, B., Smith, J., Smith, P., Sykes, M. T., Thonicke, K., Thuiller, W., Tuck, G., Zaehle, S., and Zierl, B.: Ecosystem service supply and vulnerability to global change in Europe, Science, 310, 1333-1337, doi:10.1126/science.1115233, 2005.

Schuldenrein, J., Wright, R. P., Mughal, M. R., and Khan, M. A.: Landscapes, soils, and mound histories of the Upper Indus Valley, Pakistan: new insights on the Holocene environments near ancient Harappa, J. Archaeol. Sci., 31, 777-797, 2004. 
See, L., Solomatine, D., Abrahart, R., and Toth, E.: Hydroinformatics: Computational intelligence and technological developments in water science applications - Editorial, Hydrolog. Sci. J., 52, 391-396, 2007.

Seekell, D., D'Odorico, P., and Pace, M.: Virtual water transfers unlikely to redress inequality in global water use, Environ. Res. Lett., 6, 024017, doi:10.1088/1748-9326/6/2/024017, 2011.

Seneviratne, S. I., Corti, T., Davin, E. L., Hirschi, M., Jaeger, E. B., Lehner, I., Orlowsky, B., and Teuling, A. J.: Investigating soil moisture-climate interactions in a changing climate: A review, Earth-Sci. Rev., 99, 125-161, doi:10.1016/j.earscirev.2010.02.004, 2010.

Sheffield, J. and Wood, E. F.: Projected changes in drought occurrence under future global warming from multi-model, multiscenario, IPCC AR4 simulations, Clim. Dynam., 31, 79-105, doi:10.1007/s00382-007-0340-z, 2008.

Sikorska, A. F., Montanari, A., and Koutsoyiannis, D.: Estimating the uncertainty of hydrological predictions through data-driven resampling techniques, J. Hydrol. Eng., in press, 2013.

Sivapalan, M., Blöschl, G., Zhang, L., and Vertessy, R.: Downward approach to hydrological prediction, Hydrol. Process., 17, 21012111, doi:10.1002/hyp.1425, 2003.

Sivapalan, M.: Predictions under change: Water, earth and biota in the Anthropocene, http://cwaces.geog.illinos.edu/synthesis/ reports/documents/AppendixE-PUCDraftReport.pdf (last access: December 2013), 2011.

Sivapalan, M., Savenije, H. H., and Blöschl, G.: Socio-hydrology: A new science of people and water, Hydrol. Process., 26, 12701276, 2012.

Smerdon, J. E.: Climate models as a test bed for climate reconstruction methods: pseudoproxy experiments, Wiley Interdisciplinary Reviews, Climate Change, 3, 63-77, doi:10.1002/wcc.149, 2012.

Smettem, K. R. J.: Welcome address for the new "Ecohydrology" Journal, Ecohydrology, 1, 1-2, doi:10.1002/eco.2, 2008.

Solomatine, D. and Ostfeld, A.: Data-driven modelling: some past experiences and new approaches, J. Hydroinform., 10, 3-22, 2008.

Srinivasan, V., Gorelick, S. M., and Goulder, L.: A hydrologiceconomic modeling approach for analysis of urban water supply dynamics in Chennai, India, Water Resour. Res., 46, W07540, doi:10.1029/2009WR008693, 2010a.

Srinivasan, V., Gorelick, S. M., and Goulder, L.: Sustainable urban water supply in south India: Desalination, efficiency improvement, or rainwater harvesting?, Water Resour. Res., 46, W10504, doi:10.1029/2009WR008698, 2010b.

Srinivasan, V., Lambin, E., Gorelick, S., Thompson, B., and Rozelle, S.: The nature and causes of the global water crisis: Syndromes from a meta-analysis of coupled human-water studies, Water Resour. Res., 48, W10516, doi:10.1029/2011WR011087, 2012.

Srinivasan, V., Thomas, B. K., Jamwal, P., and Lele, S.: Climate vulnerability and adaptation of water provisioning in developing countries: approaches to disciplinary and researchpractice integration, Curr. Opin. Environ. Sustainabil., 5, 378383, doi:10.1016/j.cosust.2013.07.011, 2013.

Steinman, B. A., Rosenmeier, M. F., Abbott, M. B., and Bain, D. J.: The isotopic and hydrologic response of small, closed-basin lakes to climate forcing from predictive models: Application to paleoclimate studies in the upper Columbia River basin, Limnol. Oceanogr., 55, 2131-2145, 2010.

Stephenson, N.: Actual evapotranspiration and deficit: biologically meaningful correlates of vegetation distribution across spatial scales, J. Biogeogr., 25, 855-870, 2003.

Stephenson, N. L.: Climatic control of vegetation distribution: the role of the water balance, Am. Naturalist, 649-670, 1990.

Stokes, D. E.: Pasteur's quadrant - basic science and technological innovation, Brookings Institution Press, Washington, D.C., USA, 1997.

Stokols, D., Hall, K. L., Taylor, B. K., and Moser, R. P.: The science of team science - Overview of the field and introduction to the supplement, Am. J. Prevent. Med., 35, S77-S89, doi:10.1016/j.amepre.2008.05.002, 2008.

Suen, J. P. and Eheart, J. W.: Reservoir management to balance ecosystem and human needs: Incorporating the paradigm of the ecological flow regime, Water Resour. Res., 42, W03417, doi:10.1029/2005WR004314, 2006.

Sun, F., Roderick, M. L., and Farquhar, G. D.: Changes in the variability of global land precipitation, Geophys. Res. Lett., 39, L19402, doi:10.1029/2012GL053369, 2012.

Suweis, S., Konar, M., Dalin, C., Hanasaki, N., Rinaldo, A., and Rodriguez-Iturbe, I.: Structure and controls of the global virtual water trade network, Geophys. Res. Lett., 38, L10403, doi:10.1029/2011GJ046837, 2011.

Swyngedouw, E.: The Political Economy and Political Ecology of the Hydro-Social Cycle, J. Contemp. Water Res. Educ., 142, 5660, doi:10.1111/j.1936-704X.2009.00054.x, 2009.

Taleb, N. N.: The "Black Swan" (The "Black Swan - The Impact of the Highly Improbable", Gregg Easterbrook's review), New York Times Book Review, New York, p. 4, 2007.

Tanaka, S. K., Zhu, T., Lund, J. R., Howitt, R. E., Jenkins, M. W., Pulido, M. A., Tauber, M., Ritzema, R. S., and Ferreira, I. C.: Climate warming and water management adaptation for California, Climatic Change, 76, 361-387, 2006.

Tarlock, A. D.: The Future of Prior Appropriation in the West, Nat. Resour. J., 41, p. 769, 2002.

Taylor, M. S. and Brander, J. A.: The simple economics of Easter Island: A Ricardo-Malthus model of renewable resource use, Am. Econ. Rev., 88, 119-138, 1998.

Thompson, S. and Katul, G.: Plant propagation fronts and wind dispersal: An analytical model to upscale from seconds to decades using superstatistics, Am. Naturalist, 171, 468-479, doi:10.1086/528966, 2008.

Thompson, S., Harman, C., Heine, P., and Katul, G.: Vegetationinfiltration relationships across climatic and soil type gradients, J. Geophys. Res.-Biogeo., 115, 1-27, 2010.

Thompson, S. E., Harman, C., Schumer, R., Wilson, J., Basu, N., Brooks, P., Donner, S., Hassan, M., Packman, A., and Rao, P.: Patterns, puzzles and people: implementing hydrologic synthesis, Hydrol. Process., 25, 3256-3266, 2011a.

Thompson, S. E., Harman, C. J., Konings, A. G., Sivapalan, M., Neal, A., and Troch, P. A.: Comparative hydrology across Ameriflux sites: The variable roles of climate, vegetation, and groundwater, Water Resour. Res., 47, W00j07, doi:10.1029/2010wr009797, 2011b.

Tidwell, V. C. and Van Den Brink, C.: Cooperative modeling: linking science, communication, and ground water planning, Ground Water, 46, 174-182, 2008. 
Tippett, J., Searle, B., Pahl-Wostl, C., and Rees, Y.: Social learning in public participation in river basin management - early findings from HarmoniCOP European case studies, Environ. Sci. Policy, 8, 287-299, 2005.

Torgersen, T.: Observatories, think tanks, and community models in the hydrologic and environmental sciences. How does it affect me?, Water Resour. Res., 42, W06301, doi:10.1029/2005WR004466, 2006.

Troch, P. A., Martinez, G. F., Pauwels, V., Durcik, M., Sivapalan, M., Harman, C., Brooks, P. D., Gupta, H., and Huxman, T.: Climate and vegetation water use efficiency at catchment scales, Hydrol. Process., 23, 2409-2414, 2009.

Tucker, G. E. and Slingerland, R.: Drainage basin responses to climate change, Water Resour. Res., 33, 2031-2047, doi:10.1029/97wr00409, 1997.

Tucker, G. E., Lancaster, S. T., Gasparini, N. M., and Bras, R. L.: The channel-hillslope integrated landscape development model (CHILD), in: Landscape Erosion and Evolution Modeling, edited by: Harmon, R. S. and Doe III, W. W., Kluwer/Plenum, Dordrecht, the Netherlands, 349-388, 2001.

Turner, R. E., Rabalais, N. N., and Justic, D.: Gulf of Mexico hypoxia: Alternate states and a legacy, Environ. Sci. Technol., 42, 2323-2327, 2008.

United States Geological Survey: Streamflow Information for the Nation, Department of Interior, http://pubs.usgs.gov/fs/ FS-006-97/ (last access: 24 May 2013), 1999.

van de Koppel, J., Rietkerk, M., Dankers, N., and Herman, P. M.: Scale-dependent feedback and regular spatial patterns in young mussel beds, Am. Naturalist, 165, E66-E77, 2005.

van Lanen, H. A., Demuth, S., and Servat, E.: FRIEND 2002: Regional hydrology: Bridging the gap between research and practice, International Associationn of Hydrological Sciences, Oxford, UK, 2002.

Vitousek, P. M., Aber, J. D., Howarth, R. W., Likens, G. E., Matson, P. A., Schindler, D. W., Schlesinger, W. H., and Tilman, G. D.: Human alteration of the global nitrogen cycle: Sources and consequences, Ecol. Appl., 7, 737-750, 1997.

Voepel, H., Ruddell, B. L., Schumer, R., Troch, P. A., Brooks, P. D., Neal, A., Durcik, M., and Sivapalan, M.: Hydrologic controls on catchment-scale vegetation productivity, Water Resour. Res., 47, W00J09, doi:10.1029/2010WR009944, 2011.

Vogel, R. M.: Hydromorphology, J. Water Resour. Pl. Manage., 137, 147-149, 2011.

Vogel, R. M. and Fennessey, N. M.: Flow-duration curves, I: New interpretation and confidence intervals, J. Water Resour. Pl. Manage., 120, 485-504, 1994

Vogel, R. M. and Fennessey, N. M.: Flow duration curves II: A review of applications in water resources planning, J. Am. Water Resour. Assoc., 31, 1029-1039, 1995.

Vörösmarty, C. J., Green, P., Salisbury, J., and Lammers, R. B.: Global water resources: Vulnerability from climate change and population growth, Science, 289, 284-288, 2000.

Vörösmarty, C. J., McIntyre, P. B., Gessner, M. O., Dudgeon, D., Prusevich, A., Green, P., Glidden, S., Bunn, S. E., Sullivan, C. A., Liermann, C. R., and Davies, P. M.: Global threats to human water security and river biodiversity, Nature, 468, 334334, doi:10.1038/nature09549, 2010.
Wagener, T.: Can we model the hydrological impacts of environmental change?, Hydrol. Process., 21, 3233-3236, 2007.

Wagener, T. and Montanari, A.: Convergence of approaches toward reducing uncertainty in predictions in ungauged basins, Water Resour. Res., 47, W06301, doi:10.1029/2010WR009469, 2011.

Wagener, T., Sivapalan, M., Troch, P., McGlynn, B., Harman, C., Gupta, H., Kumar, P., Rao, P. S., Basu, N., and Wilson, J.: The future of hydrology: An evolving science for a changing world, Water Resour. Res., 46, W05301, doi:10.1029/2009WR008906, 2010.

Walter, R. C. and Merritts, D. J.: Natural streams and the legacy of water-powered mills, Science, 319, 299-304, 2008.

Wang, D. and Wu, L.: Similarity of climate control on base flow and perennial stream density in the Budyko framework, Hydrol. Earth Syst. Sci., 17, 315-324, doi:10.5194/hess-17-315-2013, 2013.

Wescoat Jr., J. L.: Reconstructing the duty of water: a study of emergent norms in socio-hydrology, Hydrol. Earth Syst. Sci. Discuss. 10, 7517-7536, doi:10.5194/hessd-10-7517-2013, 2013.

Wheaton, J. M., Gibbins, C., Wainwright, J., Larsen, L., and McElroy, B.: Preface: Multiscale feedbacks in ecogeomorphology Geomorphology, 126, 265-268, doi:10.1016/j.geomorph.2011.01.002, 2011

Wolff, U.: Critical slowing down, Nucl. Phys. B, 17, 93-102, 1990.

Woodhouse, C., Meko, D., Griffin, D., and Castro, C.: Tree rings and multiseason drought variability in the lower Rio Grande Basin, USA, Water Resour. Res., 49, 844-850, doi:10.1002/wrcr.20098, 2013.

Wutich, A., White, A. C., Roberts, C. M., White, D. D., Larson, K. L., and Brewis, A.: Hard paths, soft paths or no paths? Cross-cultural perceptions of water solutions, Hydrol. Earth Syst. Sci. Discuss., 10, 7809-7835, doi:10.5194/hessd-10-7809-2013, 2013.

Yang, B., Qin, C., Shi, F., and Sonechkin, D. M.: Tree ring-based annual streamflow reconstruction for the Heihe River in arid northwestern China From AD 575 and its implications for water resource management, Holocene, 22, 773-784, 2012.

Young, P. C.: Hypothetico-inductive data-based mechanistic modeling of hydrological systems, Water Resour. Res., 49, 915-935, doi:10.1002/wrcr.20068, 2013.

Zalasiewicz, J., Williams, M., Steffen, W., and Crutzen, P.: The new world of the Anthropocene, Environ. Sci. Technol., 44, 2228 2231, doi:10.1021/es903118j, 2010.

Zhang, L., Dawes, W., and Walker, G.: Response of mean annual evapotranspiration to vegetation changes at catchment scale, Water Resour. Res., 37, 701-708, 2001.

Zhang, L., Potter, N., Hickel, K., Zhang, Y., and Shao, Q.: Water balance modeling over variable time scales based on the Budyko framework - Model development and testing, J. Hydrol., 360, 117-131, 2008.

Zhao, M., Pitman, A., and Chase, T.: The impact of land cover change on the atmospheric circulation, Clim. Dynam., 17, 467477, 2001. 